\title{
Vertically Propagating Mountain Waves-A Hazard for High-Flying Aircraft?
}

\author{
MARTinA BRAmberger, ANDreas DÖRnBrack, AND HENRIKE Wilms \\ Deutsches Zentrum für Luft- und Raumfahrt, Institut für Physik der Atmosphäre, Oberpfaffenhofen, Germany \\ STEFFEN GEMSA a AND KEVIN RAYNOR \\ Deutsches Zentrum für Luft- und Raumfahrt, Flugexperimente, Oberpfaffenhofen, Germany \\ ROBERT SHARMAN \\ National Center for Atmospheric Research, ${ }^{\mathrm{b}}$ Boulder, Colorado
}

(Manuscript received 8 December 2017, in final form 5 June 2018)

\begin{abstract}
Stall warnings at flight level $410(12.5 \mathrm{~km})$ occurred unexpectedly during a research flight of the High Altitude and Long Range Research Aircraft (HALO) over Italy on 12 January 2016. The dangerous flight situation was mitigated by pilot intervention. At the incident location, the stratosphere was characterized by large horizontal variations in the along-track wind speed and temperature. On this particular day, strong northwesterly winds in the lower troposphere in concert with an aligned polar front jet favored the excitation and vertical propagation of large-amplitude mountain waves at and above the Apennines in Italy. These mountain waves carried large vertical energy fluxes of $8 \mathrm{~W} \mathrm{~m}^{-2}$ and propagated without significant dissipation from the troposphere into the stratosphere. While turbulence is a well-acknowledged hazard to aviation, this case study reveals that nonbreaking, vertically propagating mountain waves also pose a potential hazard, especially to high-flying aircraft. It is the wave-induced modulation of the ambient along-track wind speed that may decrease the aircraft speed toward the minimum needed stall speed.
\end{abstract}

\section{Introduction}

Tropospheric weather strongly influences aviation in different ways. At ground, high temperatures limit the takeoff weights of airplanes (Coffel and Horton 2015). Thunderstorms together with lightning strikes can cause disruptions and delays in the operation of airports (Romps et al. 2014). In the upper troposphere and lower stratosphere where most commercial aircraft fly, shifting wind patterns may modify optimal flight routes, which in turn affect travel times (Karnauskas et al. 2015; Irvine et al. 2016; Kim et al. 2016; Williams 2016). Moreover, at these altitudes atmospheric turbulence is the major

\footnotetext{
${ }^{\text {a }}$ Current affiliation: Flight Test Department, RUAG Aerospace Services GmbH, Weßling, Germany.

${ }^{\mathrm{b}}$ The National Center for Atmospheric Research is sponsored by the National Science Foundation.
}

Corresponding author: Martina Bramberger, martina.bramberger@ dlr.de reason for injuries to passengers and crew (Sharman et al. 2012b; Tvaryanas 2003). In particular, unpredicted turbulence outside clouds can be hazardous as it is neither visible to pilots nor detectable by standard onboard radars (Sharman et al. 2012b). This kind of turbulence that is not connected to clouds and thunderstorms is referred to as clear-air turbulence (CAT).

Well-known generation processes of turbulence affecting aircraft at cruising altitudes comprise thunderstorms, strong wind shears related to upper-level fronts and jet streams, unbalanced flow, and breaking mountain waves (e.g., Vinnichenko et al. 1980; Lester 1993; Wolff and Sharman 2008; Lane et al. 2012; Sharman et al. 2012b). Considering the generation process, turbulence directly related to breaking mountain waves is referred to as mountain wave turbulence (MWT) (Sharman et al. 2012b).

Apart from clouds and the vicinity of thunderstorms, Wolff and Sharman (2008) identified regions susceptible to turbulence over the United States. Preferred areas for turbulence occurrence are complex terrains such as the 
Rocky Mountains where the source of turbulence could be attributed to mountain wave breaking. Other regions posing wave-induced hazards to aviation include, for example, the Alps (e.g., Jiang and Doyle 2004) and Greenland (e.g., Doyle et al. 2005; Ólafsson and Ágústsson 2009; Lane et al. 2009; Sharman et al. 2012a). Greenland is of particular importance as it is located underneath the highly frequented North Atlantic flight tracks connecting Europe and North America.

The Graphical Turbulence Guidance (GTG) product provides automated, aircraft-type-independent turbulence forecasts for CAT and MWT at all flight levels (FL) from surface to the lower stratosphere (FL500; "500" indicates $50000 \mathrm{ft}$, with $1 \mathrm{ft} \approx 0.3 \mathrm{~m}$ ) (Sharman et al. 2006; Sharman and Pearson 2017). In this framework, the forecasts of MWT are calculated by a simple multiplication of the CAT prediction with a terraindependent quantity. This approach takes into account that mountain waves-and, in particular, the breaking of mountain waves - are well-known processes that impact aviation (e.g., Bacmeister et al. 1990; Schmid and Dörnbrack 1999; Leutbecher and Volkert 2000). On the other hand, state-of-the-art numerical weather prediction (NWP) models attain horizontal resolutions of less than $10 \mathrm{~km}$. Thus, high-resolution global data are a valuable source for detecting and predicting mountain waves. Dörnbrack et al. (2017) showed that the recent increase of horizontal resolution of the Integrated Forecast System (IFS) of the European Centre for MediumRange Weather Forecasts (ECMWF) led to a realistic simulation of wave-induced mesoscale temperature anomalies. Moreover, they concluded that the remarkable agreement of the simulated wave structure in the IFS short-term forecast and the spaceborne observations of polar stratospheric clouds indicates a fundamental trend: the finer resolution and increasing realism of operational NWP model outputs offers a valuable quantitative source for mesoscale flow components that were heretofore not accessible globally (Bauer et al. 2015).

The importance of mountain waves, not only to aviation safety but for the general atmospheric circulation from the boundary layer to the middle atmosphere (e.g., through the transport and deposition of momentum), is well established (e.g., Fritts and Alexander 2003). Therefore, numerous campaigns devoted to enhancing the scientific knowledge of mountain wave excitation, propagation, and dissipation have been conducted. Among these are the Momentum Budget over the Pyrénées Experiment (PYREX; Bougeault et al. 1990, 1993), the Mesoscale Alpine Programme (MAP; Bougeault et al. 2001), the Terrain-Induced Rotor Experiment (T-REX; Grubišić et al. 2008), the Gravity Wave Life Cycle I (GW-LCYCLE I) campaign (Wagner

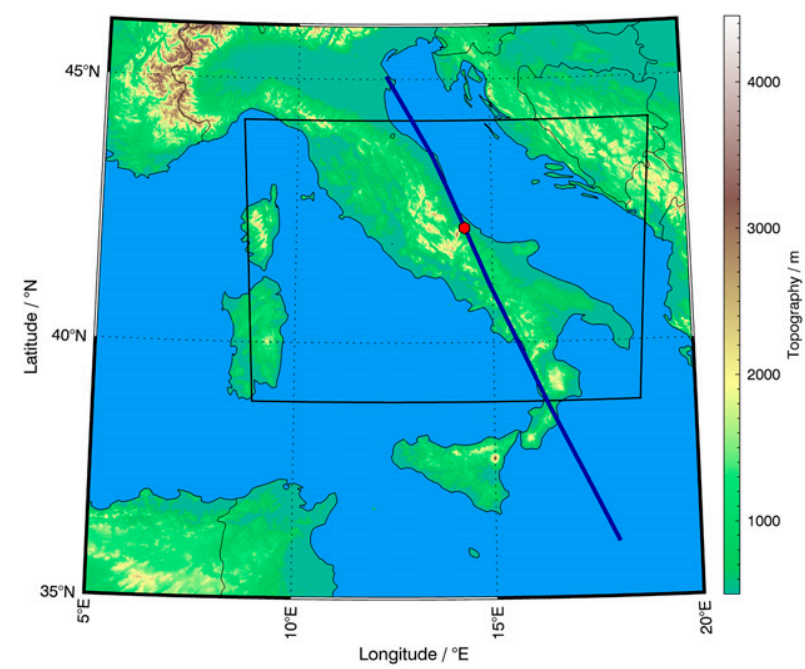

FIG. 1. Flight track above Italy (dark-blue line). The red circle shows the location of the stall warnings, and the box outlined in black displays the computational domain of the EULAG simulations. Flight direction was from north to south. The topography is the global relief model ETOPO1 and also was used in the highresolution numerical simulations.

et al. 2017), and the Deep Propagating Gravity Wave Experiment (DEEPWAVE) (Fritts et al. 2016). In the same spirit of the preceding field campaign, the Gravity Wave Life Cycle II (GW-LCYCLE II) experiment took place above northern Scandinavia from January to March 2016 (special issue in Atmospheric Chemistry and Physics: Sources, Propagation, Dissipation and Impact of Gravity Waves; https://www.atmos-chem-phys.net/ special_issue899.html).

During its extended transfer flight to the operational base, the High Altitude and Long Range Research Aircraft (HALO) encountered a series of stall warnings above the Apennines in Italy on 12 January 2016. HALO flew from north to south at an altitude of $12.5 \mathrm{~km}$ [height above World Geodetic System 1984 (WGS84) ellipsoid], which on that day was at FL410 (see Fig. 1). The pilots expected calm stratospheric flying conditions when, after a significant loss of the actual flown Mach number (Ma) within approximately $10-20 \mathrm{~s}$, several stall warnings were issued by the autopilot system. Simultaneously, large variations in the along-track wind speed and static air temperature were observed. The flight situation was mitigated by the pilots, who descended to a lower flight level.

In general, what causes stall events? In a diagram of altitude versus aircraft speed, aircraft design together with the ambient density allow safe flights only inside an envelope limited by the aerodynamic lift (lower limit) and the airspeed (upper limit), respectively (see section a and Fig. A1 of the appendix). The lift limit is on the left side of the flight envelope, and it also gives the 
minimum, level-flight airspeed, which is defined as the stall speed (Corda 2017). If the aircraft speed is reduced below the stall speed, the aircraft's wings cannot produce enough lift to balance the weight, as the flow over the wings separates and, consequently, the aircraft stalls. The upper speed limit is given by the right branch in the flight envelope and is called maximum operating Mach number. In this case, the maximum available thrust of the engines and aerodynamic aspects contribute to this limit (Corda 2017). As air density decreases with altitude, the available thrust is reduced with increasing flight levels (Brandt et al. 2004). From an aerodynamic point of view, shock waves can evolve over the wing, which on the one hand destroy the lift as a result of flow separation and on the other hand could cause controllability issues depending on their position with respect to the wing (Mach tuck). These shock waves form at transonic flow speeds over the wings $(\mathrm{Ma} \approx 1)$. Because Ma is indirectly proportional to the speed of sound, which in turn depends on the air temperature, the Ma at which shock waves form decreases with increasing altitudes. For high-flying aircraft such as, for example, HALO, the stall speed and the maximum operating Ma nearly converge at the maximum possible flight altitude, a region that is called "coffin corner" by pilots (Corda 2017). However, the actual flown Ma depends not only on the ambient temperature but also on the horizontal wind speed in the along-track direction through Eq. (A1) (see section b of the appendix). That way, aircraft flying in proximity of the coffin corner might be easily affected by sudden and unexpected temperature and/or horizontal wind variations that could bring the aircraft speed close to the stall speed or the maximum operating Ma.

With regard to our own stall event, we raise the following questions: Are the observed along-track variations in the meridional wind component and temperature responsible for initiating of the stall-warning event? Are these variations induced by mesoscale processes as propagating mountain waves or are they due to largescale meteorological processes? Are the observed fluctuations accurately reproduced by high-resolution IFS forecasts and analyses? Which dominating processes can be identified on the basis of higher-resolved mesoscale numerical simulations? Does the GTG predict mountain wave-induced turbulence associated with the forecast fluctuations? Since HALO was equipped with a scientific payload, various high-quality sensors can be used to quantify the turbulence as well as the energy contained in the mountain waves. This opens the possibility to compare predicted energy dissipation rates with observed ones.

The remainder of this paper describes the applied methods and models in section 2 followed by a detailed account of the sequence of events before and during the
TABLE 1. Overview of the measurement uncertainties for different parameters of HALO in situ measurements.

\begin{tabular}{lc}
\hline \hline & $\begin{array}{c}\text { Measurement } \\
\text { uncertainty }\end{array}$ \\
\hline Static pressure & $30 \mathrm{~Pa}$ \\
Static temperature & $0.5 \mathrm{~K}$ \\
Horizontal wind & $0.5 \mathrm{~m} \mathrm{~s}^{-1}$ \\
Vertical wind $w$ & $0.3 \mathrm{~m} \mathrm{~s}^{-1}$ \\
\hline
\end{tabular}

stall warnings (section 3). Afterward the meteorological situation (section 4) and in situ measurements are analyzed with regard to mountain wave (section 5) and turbulence characteristics (section 6), followed by results of high-resolution numerical simulations (section 7). A discussion with conclusions in section 8 completes the paper.

\section{Methods and model description}

Airborne in situ flight-level data from HALO, operational analyses, and short-term forecasts of ECMWF's IFS, high-resolution idealized numerical simulations with the Eulerian/semi-Lagrangian fluid solver (EULAG), as well as the GTG are employed to analyze HALO's incident.

\section{a. Flux calculations}

HALO is equipped with the Basic HALO Measurement and Sensor System (BAHAMAS), which provides measurements of pressure, temperature, and the three wind components (Giez et al. 2016). For this case study, data sampled at $10 \mathrm{~Hz}$ with a horizontal resolution of about $50 \mathrm{~m}$ are available. The measurement uncertainties are given in Table 1 and were calculated with the procedure described in Mallaun et al. (2015). These in situ measurements at flight level are used to calculate local values of the vertical energy flux $\mathrm{EF}_{z}$ and the vertical fluxes of horizontal momentum $\mathrm{MF}_{x}$ and $\mathrm{MF}_{y}$ applying two different approaches. One method calculates leg-integrated values of $\mathrm{MF}_{x}$, and $\mathrm{MF}_{y}$ by

$$
\mathrm{MF}_{x}=\frac{\bar{\rho}}{s} \int_{0}^{s} u^{\prime} w^{\prime} d s \text { and } \mathrm{MF}_{y}=\frac{\bar{\rho}}{s} \int_{0}^{s} v^{\prime} w^{\prime} d s,
$$

in units of pascals, and of $\mathrm{EF}_{z}$ by

$$
\mathrm{EF}_{z}=\frac{1}{s} \int_{0}^{s} p^{\prime} w^{\prime} d s
$$

in units of watts per meter squared according to Smith et al. (2008). Here, $\bar{\rho}$ denotes the mean density along the leg and $u^{\prime}, v^{\prime}$, and $w^{\prime}$ are the perturbations of the zonal, meridional, and vertical wind components, respectively. The zonal and meridional components of the vertical momentum flux vector $\mathbf{M F}$ are given by $\mathrm{MF}_{x}$ and $\mathrm{MF}_{y}$. 
Assuming nonresonant, vertically propagating internal gravity waves in a steady flow with no critical layers, the Eliassen-Palm relation

$$
\mathrm{EF}_{z}=-\left(\bar{u} \mathrm{MF}_{x}+\bar{v} \mathrm{MF}_{y}\right) \equiv \mathrm{EF}_{z M}
$$

can be applied to test the linearity of the sampled wave field (Eliassen and Palm 1961). The overbars in this relation indicate leg averages of the respective horizontal wind component.

The pressure $p$ used for calculating $\mathrm{EF}_{z}$ was hydrostatically corrected; for further information see Smith et al. $(2008,2016)$. The perturbation quantities $u^{\prime}, v^{\prime}, w^{\prime}$, and $p^{\prime}$ are calculated from the flight-level data $u, v, w$, and $p$ by subtracting linear least squares fits (Bramberger et al. 2017). This approach removes large-scale gradients, for example, when HALO is crossing synoptic-scale weather systems. These fluxes will be referred to as legintegrated fluxes. For this study, the fluxes defined in Eqs. (1) and (2) are only calculated after the stall-warning event, south of $40.7^{\circ} \mathrm{N}$, when stable flight conditions were reestablished. This was done to include as many mountain wave scales as possible in our analysis because the horizontal distance of the stall-warning event would have limited the maximum observable horizontal wavelength.

The second approach is used to access the spatial variability of the energy and momentum fluxes along the north-south leg. For this purpose, the flight leg is subdivided into smaller sublegs with a length of $88 \mathrm{~km}$ and for each of these sublegs the fluxes are calculated individually using Eqs. (1) and (2). In the following, these fluxes are referred to as subleg-integrated fluxes. The averages of the subleg-integrated momentum and energy fluxes differ from the leg-integrated fluxes since different scales are captured by the two methods and different linear fits are subtracted from the flight-level data.

The spectral analysis of the energy fluxes of the observed mountain waves is based on the wavelet spectra (Torrence and Compo 1998). Following Woods and Smith (2010), the Morlet wavelet of order 6 is used as mother wavelet and the cospectra of the energy and momentum fluxes are calculated by

$$
\begin{aligned}
\widetilde{\mathrm{EF}}_{n}\left(s_{j}\right) & =\Re\left\{\tilde{P}_{n}\left(s_{j}\right) \tilde{W}_{n}^{*}\left(s_{j}\right)\right\} \quad \text { and } \\
\widetilde{\mathrm{MF}}_{x n}\left(s_{j}\right) & =\bar{\rho} \times \Re\left\{\tilde{U}_{n}\left(s_{j}\right) \tilde{W}_{n}^{*}\left(s_{j}\right)\right\},
\end{aligned}
$$

where an appropriate scaling of $\tilde{P}_{n}\left(s_{j}\right)$ and $\tilde{W}_{n}\left(s_{j}\right)$ assures that the unit of $\widetilde{\mathrm{EF}}_{n}\left(s_{j}\right)$ is watts per meter squared (Bramberger et al. 2017) and $\Re\{$ denotes the real part. The quantities $\tilde{P}_{n}\left(s_{j}\right)$ and $\tilde{U}_{n}\left(s_{j}\right)$ are the wavelet transforms of $p^{\prime}$ and $u^{\prime}$ at spatial index $n$ for the wavelet scale $s_{j}$ at wavenumber index $j$. Here, $\tilde{W}_{n}^{*}\left(s_{j}\right)$ denotes the complex conjugate of the wavelet transform of $w^{\prime}$.

\section{b. Scorer parameter}

To estimate the critical horizontal wavelength $\lambda_{c}$ allowing vertical propagation of linear gravity waves under the given ambient atmospheric conditions, the Scorer parameter is used. Here, the calculation is based on ECWMF spectrally truncated data up to wavenumber 21 with two different approaches:

$$
\ell_{U}^{2}=N^{2} / U^{2},
$$

with the static stability $N$ and the horizontal wind $U=\left(u^{2}+v^{2}\right)^{1 / 2}$, and

$$
\ell_{u}^{2}=N^{2} / u^{2},
$$

where $u$ is the zonal wind component. The presented profiles are taken at $40^{\circ}$ and $42^{\circ} \mathrm{N}$, respectively, and the data have been averaged in the zonal direction between $10^{\circ}$ and $11.5^{\circ} \mathrm{E}$.

\section{c. Turbulence parameters}

To characterize atmospheric turbulence two different parameters are derived from the in situ measurements at flight level: the turbulent kinetic energy (TKE) and the cube root of the energy dissipation rate or $\varepsilon^{1 / 3}$, which is referred to as EDR. The parameter EDR is particularly useful because it can be related to aircraft-specific loads enabling calibration of EDR to different aircraft types in terms of aircraft response (MacCready 1964; Cornman et al. 1995; Sharman et al. 2014; Cornman 2016). Furthermore, EDR is the International Civil Aviation Organization (ICAO 2001) standard for aviation turbulence reporting. The ICAO document also provides estimates of "light," "moderate," "severe," and "extreme" turbulence intensity thresholds for a medium-weight class aircraft. Turbulence thresholds used in this study are for a medium-size aircraft, which might be a little high for a light aircraft such as HALO (Sharman et al. 2014).

Note that the horizontal wind components were transformed into an aircraft coordinate system for the calculation of TKE and EDR in order to be consistent with former studies, such as, for example, Strauss et al. (2015). Thus, for this analysis $u_{\mathrm{ac}}$ refers to the longitudinal (along track) and $v_{\mathrm{ac}}$ refers to the transverse (cross track) horizontal wind component with respect to the aircraft.

The TKE per unit mass is calculated by TKE $=$ $\left(\sigma_{u_{\mathrm{ac}}}^{2}+\sigma_{v_{\mathrm{ac}}}^{2}+\sigma_{w}^{2}\right) / 2$, that is, as one-half of the sum of the variances of the wind fluctuations along the leg. For our analysis the TKE is calculated for different subleg lengths ranging between about 20 and $4 \mathrm{~km}$.

The calculation of EDR is based on Strauss et al. (2015) who used the inertial dissipation technique 
(Champagne 1978; Piper and Lundquist 2004; Večenaj et al. 2012), which is a method that takes into account the Kolmogorov form of the turbulent energy spectrum. In this framework, the spectral energy density $S_{i}$ for the respective component of the wind velocity vector $\mathbf{u}_{i}=$ $\left\{\mathrm{u}_{\mathrm{ac}}, v_{\mathrm{ac}}, w\right\}$ is given by

$$
S_{i}(k)=\alpha_{i} \varepsilon^{2 / 3} k^{-5 / 3},
$$

where $k$ is the wavenumber, $i$ is the index of the respective component of the wind velocity vector, and $\alpha_{i}=\{0.53,0.707,0.707\}$ are the Kolmogorov constants (Oncley et al. 1996; Piper and Lundquist 2004; Strauss et al. 2015). With the help of Eq. (8), the EDR can be computed from the spectrum of each wind velocity component $\mathbf{u}_{i}$ by

$$
\mathrm{EDR}_{i}=\varepsilon_{i}^{1 / 3}=\left[\overline{S_{i}(k) k^{5 / 3}}\right]^{1 / 2}
$$

In contrast to Strauss et al. (2015) who used sublegs of $2 \mathrm{~km}$, we divide the complete flight leg into longer sublegs with a length of $4 \mathrm{~km}$ because the $10-\mathrm{Hz}$ sampling frequency of our dataset is lower than the data resolution in their study $(25 \mathrm{~Hz})$. Applying Welch's method (Welch 1967), each of these 4-km sublegs is subdivided into three overlapping segments. The data are linearly detrended on these segments, a Tukey window is applied, and the spectral energy density is calculated with a fast Fourier transform. Note, the quantity $S_{i}$ used to calculate EDR according to Eq. (9) is an arithmetic mean of the spectral energy densities over these three overlapping segments that is denoted by the overbar. Furthermore, we define a fixed frequency range between 0.1 and $2 \mathrm{~Hz}$ within which EDR is calculated. This fixed frequency range is a compromise between taking into account as much data as possible with less variance in the spectral slope but excluding artifacts that could be due to aliasing, digital noise, or other sources. The mean spectral slope in this frequency range for the spectral energy density of the vertical wind is -1.33 with a variance of 0.46 .

With the $\mathrm{EDR}_{i}$ of each wind velocity component $\mathbf{u}_{i}$ we estimate a "log mean" EDR, or $\overline{\mathrm{EDR}}$, by

$$
\begin{aligned}
\log (\overline{\mathrm{EDR}})= & {\left[\log _{10}\left(\mathrm{EDR}_{u_{\mathrm{ac}}}\right)+\log _{10}\left(\mathrm{EDR}_{v_{\mathrm{ac}}}\right)\right.} \\
& \left.+\log _{10}\left(\mathrm{EDR}_{w}\right)\right] / 3 .
\end{aligned}
$$

\section{d. High-resolution meteorological fields}

To describe the synoptic situation during the flight, hourly short-term forecasts and 6-hourly operational analyses of the deterministic high-resolution IFS runs are combined to generate a continuous dataset for the 12 January 2016 case. The IFS model is a global, hydrostatic semi-implicit, semi-Lagrangian NWP model. Here, the high-resolution analyses and forecasts of the preoperational IFS cycle $41 \mathrm{r} 2$ are used (see https://www. ecmwf.int/en/forecasts/documentation-and-support/ changes-ecmwf-model for the detailed documentation of the specific IFS cycles). The former operational IFS cycle 41r1 utilized a linear Gaussian grid with a spectral truncation at wavenumber $1279\left(\mathrm{~T}_{\mathrm{L}} 1279\right)$, which corresponds to a horizontal resolution of $\Delta x \approx 16 \mathrm{~km}$. The horizontal resolution of all different operational applications using the IFS were increased when the IFS cycle 41r1 was replaced by cycle 41r2 on 8 March 2016 (Hólm et al. 2016). The corresponding high-resolution analyses and forecasts are computed on a cubic octahedral grid with $\Delta x \approx 9 \mathrm{~km}$ while the spectral truncation remained at wavenumber $1279\left(\mathrm{~T}_{\mathrm{Co}} 1279\right.$; Malardel and Wedi 2016). [Wedi (2014) and Malardel and Wedi (2016) contain more explanation about linear and cubic grids.] Other sources for the gain in effective resolution are the reduced numerical filtering in the model and the preparation of physiographic data at the surface. During January 2016, the IFS cycle 41r2 was running preoperationally in parallel and all data were archived at the ECMWF. In the vertical, 137 levels range from the model top at a pressure level of $0.01 \mathrm{hPa}(\approx 80-\mathrm{km}$ altitude) down to the surface ( $\approx 10$-m altitude). In the lower stratosphere, the vertical resolution is about $500 \mathrm{~m}$. Two datasets with different spectral resolutions are retrieved and interpolated on the same regular $0.125^{\circ} \times 0.125^{\circ}$ latitude/longitude grid. For presenting the high-resolution fields, the highest available spectral resolution of $\mathrm{T}_{\mathrm{Co}} 1279$ is used.

\section{e. Eulerian/semi-Lagrangian fluid solver}

To assess the magnitude of mountain wave-induced perturbations above the Apennines, we conducted highresolution, quasi-realistic numerical simulations with the multiscale geophysical flow solver EULAG (Prusa et al. 2008). For this analysis, a time period was selected after a quasi-steady state of the numerical integrations was achieved.

EULAG solves the anelastic equations (Prusa et al. 2008) and the equations for the TKE (Sorbjan 1996) in terrain-following coordinates. The computational grid is centered around the stall-warning event (see Fig. 1) and comprises $336 \times 240 \times 76$ grid points in the zonal, meridional, and vertical dimension, respectively. The horizontal resolution is $2.5 \mathrm{~km}$, the vertical resolution is $500 \mathrm{~m}$, and the time step is $5 \mathrm{~s}$. The topography is the global relief model (ETOPO1; Amante and Eakins 2009) (see Fig. 1) with a horizontal resolution of 1 arc min, 
which is linearly interpolated onto the computational grid of EULAG.

The initial and boundary conditions of horizontal wind speed and potential temperature are given by single profiles of each, extracted from ECMWF spectrally truncated data up to wavenumber 21 (T21). These profiles are a zonal mean from $10^{\circ}$ to $11.5^{\circ} \mathrm{E}$ taken upstream of the stall-warning event at $42^{\circ} \mathrm{N}$ and 0600 UTC. Figure 4, described in more detail below, shows the horizontal wind profile that was used as input for EULAG. The initialization with a single, hydrostatically balanced state neglects large-scale meridional gradients such as the change in tropopause altitude (see Figs. $3 \mathrm{c}$ and $3 \mathrm{~d}$, below). However, all perturbations can be attributed to the applied forcing of the flow across the Apennines. In the following and in the context of the EULAG simulations, perturbations are defined as the deviation from the initial conditions. Because of the idealized approach of these simulations, one cannot expect to find a one by one agreement between the in situ measurements and the simulations. We aim instead at understanding whether vertically propagating mountain waves can induce wind and temperature perturbations at flight level and on horizontal scales comparable to the observations.

\section{f. Graphical turbulence guidance system}

Turbulence forecasts of the GTG as presented in this paper are calculated from the operational IFS shortterm forecasts. The way the GTG is designed, it depends on the scale of the input NWP, and cannot actually resolve turbulence. Instead, the GTG uses an ensemble of many different CAT diagnostics describing different physical processes under the assumption that a downscale cascade from the larger resolved scales to the aircraft scales exists. All the different diagnostic quantities are projected to one common, aircraft-typeindependent forecast parameter, the EDR. There are two GTG turbulence forecast products: EDR predictions of CAT and MWT, respectively. For these forecasts, the term CAT is used in a more general way and includes any diagnostic that successfully identifies large spatial gradients of atmospheric state parameters, regardless of their generation mechanism or their location with respect to clouds. Thus, the CAT diagnostic also includes other sources apart from Kelvin-Helmholtz instabilities such as, for example, convective systems. To forecast MWT, the GTG multiplies the CAT diagnostics with a parameter related to the terrain height and low-level wind speed. A detailed description of the GTG and its statistical forecast skill can be found in Sharman et al. (2006) and Sharman and Pearson (2017).

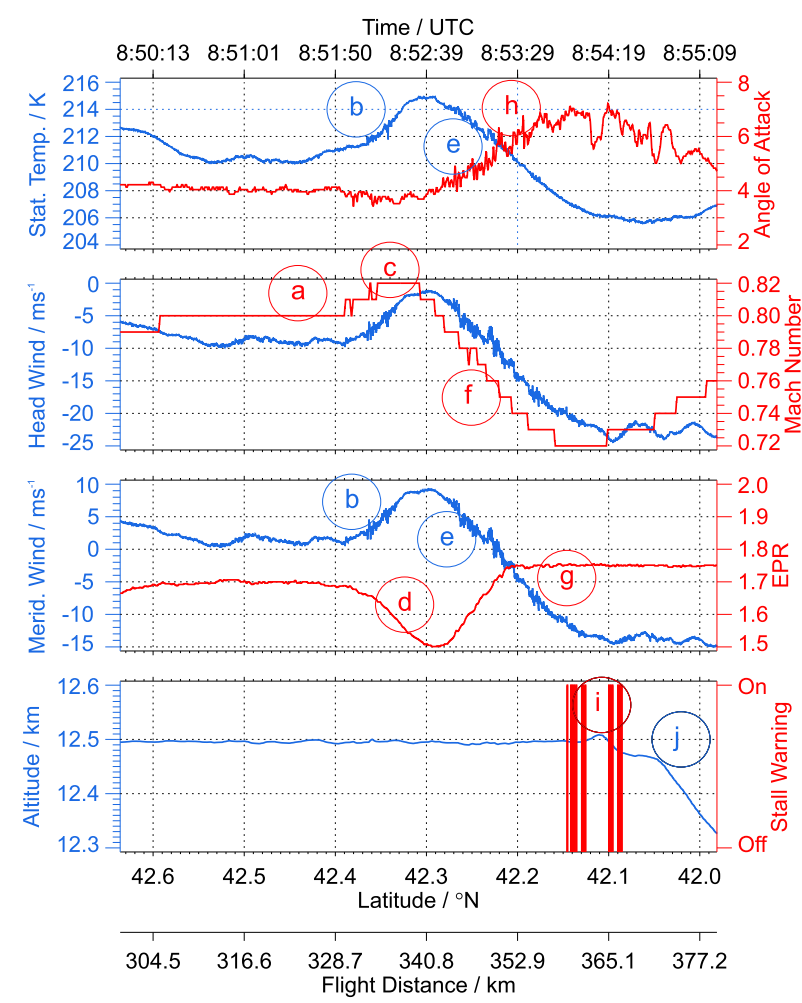

FIG. 2. Sequence of events as recorded by HALO's QAR and the BAHAMAS: (top) static air temperature (blue) and the angle of attack (red), (top middle) the head wind (blue) and Mach number (red), (bottom middle) the meridional wind (blue) and the EPR (red), and (bottom) the flight altitude (blue) and stall warning (red). The letters a-j refer to the sequence of events leading to the stall warnings as mentioned in the text. The QAR dataset comprises the angle of attack, Ma, EPR, and stall warning. BAHAMAS data include temperature, altitude, and meridional and head winds.

\section{Flight incident}

This section uses data from the quick-access recorder (QAR) and the BAHAMAS to describe the sequence of events leading to several stall warnings (Fig. 2). During the incident the heading of the aircraft was $170^{\circ}$ and therefore the meridional component of the horizontal wind is analyzed.

HALO took off from Oberpfaffenhofen, Germany $\left(48.08^{\circ} \mathrm{N}, 11.28^{\circ} \mathrm{E}\right)$, at $0755 \mathrm{UTC}$. The cruising altitude of the southbound leg on FL410 was reached over the central Alps after about $30 \mathrm{~min}$. To understand the sequence of events leading to the stall-warning event, the initial situation of the aircraft and the changes in the atmospheric background conditions along the flight track are of major importance.

At about 0850 UTC, HALO was flying through an area with gradually decreasing static air temperature. The lower atmospheric temperature increased the air density, which in turn increased the lift of the wings and 
eventually the thrust of the engines (see sections $\mathrm{c}$ and $\mathrm{d}$ of the appendix). By this way, the aircraft accelerated and the autopilot reduced the angle of attack to keep the aircraft at constant speed. This means that HALO was already in an accelerated state (Fig. 2, point a) when it entered a region with large along-track gradients in both the static air temperature and meridional wind speeds.

While the angle of attack was being reduced, the atmospheric temperature increased by about $5 \mathrm{~K}$ at 0852 UTC (Fig. 2, point b), which reduced the air density and, thus, the lift and thrust. At the same time, the meridional wind increased by about $8 \mathrm{~m} \mathrm{~s}^{-1}$, reducing the tailwind (negative headwind) from about 10 to $2 \mathrm{~m} \mathrm{~s}^{-1}$ in this segment of the flight. As the actual flown Ma is proportional to the relative speed of the aircraft to the air (see the section b of the appendix), this increased the Ma to values larger than the appointed aircraft speed (Fig. 2, point c). Consequently, HALO's autothrottle reduced the thrust of the engines to decelerate the aircraft (Fig. 2, point d).

During the deceleration of the aircraft, the ambient atmospheric conditions changed again with a decrease in temperature by $9 \mathrm{~K}$ and a reduction in the meridional wind of about $20 \mathrm{~m} \mathrm{~s}^{-1}$ (Fig. 2, point e). The decrease of the meridional wind not only reduced its value but also changed the direction from southerly to northerly, and consequently the magnitude of the tailwind of the aircraft increased by $20 \mathrm{~m} \mathrm{~s}^{-1}$. The reduced thrust together with the increased tailwind decelerated HALO gradually by $0.1 \mathrm{Ma}$ within about $1.5 \mathrm{~min}$, thus reducing the margin to the stall speed (Fig. 2, point f). HALO's autothrottle adjusted to the situation and accelerated fully to the maximum engine power ratio (EPR) of 1.6 (Fig. 2, point $\mathrm{g}$ ). However, this measure alone was not sufficient to regain the appointed aircraft speed because of the low air density at this altitude and the time lag of the autothrottle system. Because the autopilot is programmed to preserve the flight altitude, it continued to increase the angle of attack to raise the lift of the aircraft (Fig. 2, point h). In the end, the angle of attack was large enough that flow could separate over the wings and the autopilot issued several stall warnings (Fig. 2, point i). The pilots mitigated the situation by switching off the autopilot and descending to a lower flight level in order to regain safe flight conditions (Fig. 2, point j). During this incident, the pilots reported only light turbulence.

As documented above, the observed variations of ambient wind and temperature can explain the aircraft behavior and the reactions of the autopilot system. These variations occurred at spatial scales of less than $100 \mathrm{~km}$, raising the question of what processes did cause these changes in ambient conditions.

\section{Meteorological situation}

On 12 January 2016, the day of the flight incident, northwesterly near-surface winds were present in the Mediterranean Sea region (Figs. 3a,b). This direction of the low-level flow was almost perfectly normal to the mean terrain crests. Flow channeling over the French Alps enhanced the horizontal winds over Corsica and Tuscany to speeds exceeding $10 \mathrm{~m} \mathrm{~s}^{-1}$. Thus, the direction and strength of the surface flow provided favorable low-level forcing conditions for the excitation of mountain waves in this region.

In the upper troposphere, a large-scale trough was located above northern Italy and middle Europe, leading to a sharp north-south gradient of the height of the dynamical tropopause (Figs. 3c,d). An elongated tropopause fold together with the strong polar front jet $\left(U \approx 80 \mathrm{~m} \mathrm{~s}^{-1}\right.$ ) extended zonally from southern France to Italy along about $42^{\circ} \mathrm{N}$. During the flight of HALO, this meteorological system propagated slowly southeastward. Thus, HALO's flight track at FL410 passed from the stratosphere in the north, across the tropopause over northern Italy, and into the troposphere above southern Italy (Figs. 3c,d).

The alignment of lower-tropospheric winds and of the polar front jet favored the vertical propagation of the excited mountain waves in two ways: first, the background horizontal wind speed increased with altitude (Fig. 4), and, second, there was very little directional shear up to the lower stratosphere. That way, no critical layer attenuated the propagation of mountain waves by nonlinear processes such as wave breaking. Between 0600 and 0900 UTC maximum wind speeds increased only slightly from 76 to $78 \mathrm{~ms}^{-1}$. Assuming a mean background wind of approximately $30 \mathrm{~m} \mathrm{~s}^{-1}$ it takes hydrostatic mountain waves with $\lambda_{h} \approx 50 \mathrm{~km}$ about $0.75 \mathrm{~h}$ to propagate from the surface to an altitude of $15 \mathrm{~km}$. Therefore, background conditions for the vertical propagation of hydrostatic mountain waves into the lower stratosphere can be assumed steady within this time frame.

High-resolution IFS analyses of the vertical wind reveal coherent waves at the $150-\mathrm{hPa}$ pressure level over the French Alps, Corsica, and the Apennines, respectively (Figs. 3e,f). These wave patterns are stationary with respect to the particular mountain ranges. Because of their stationary character and the hydrostatic design of the IFS, they can be attributed to vertically propagating hydrostatic mountain waves. Correspondingly, undulations of the geopotential height as depicted in Figs. $3 \mathrm{e}$ and $3 \mathrm{f}$ are related to these mountain waves. Simulated mountain wave amplitudes of the vertical wind decrease from about 1 to about $0.5 \mathrm{~m} \mathrm{~s}^{-1}$ from 0600 
6 UTC

a)

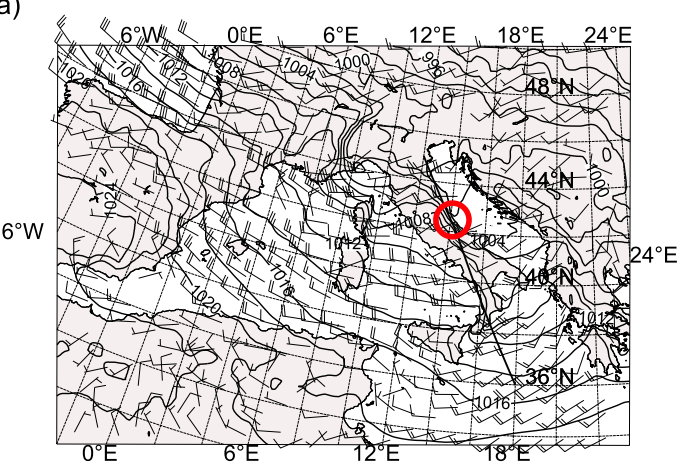

c)

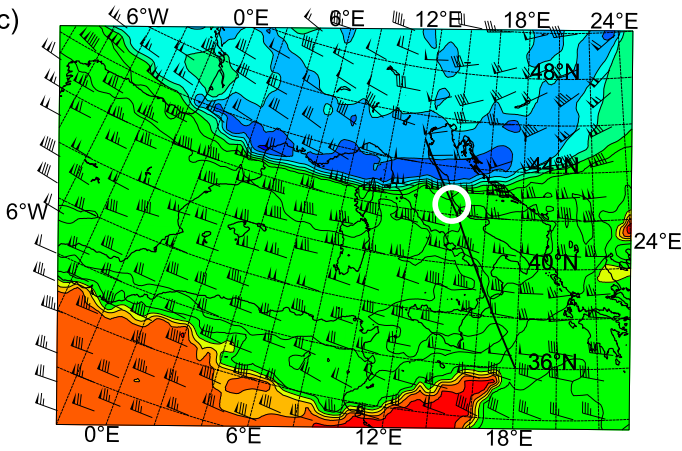

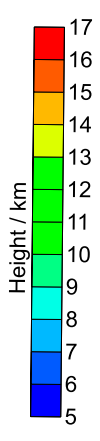

e)

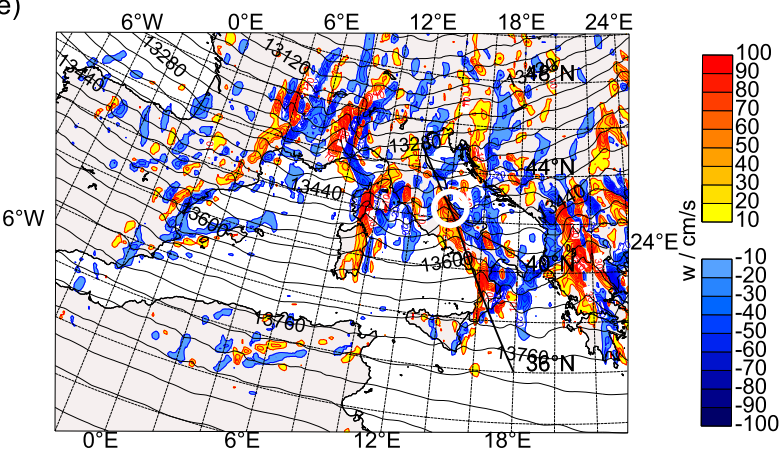

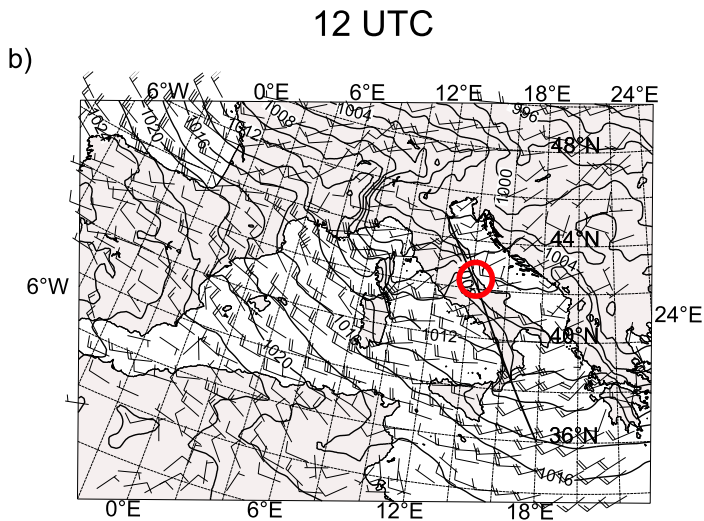

d)

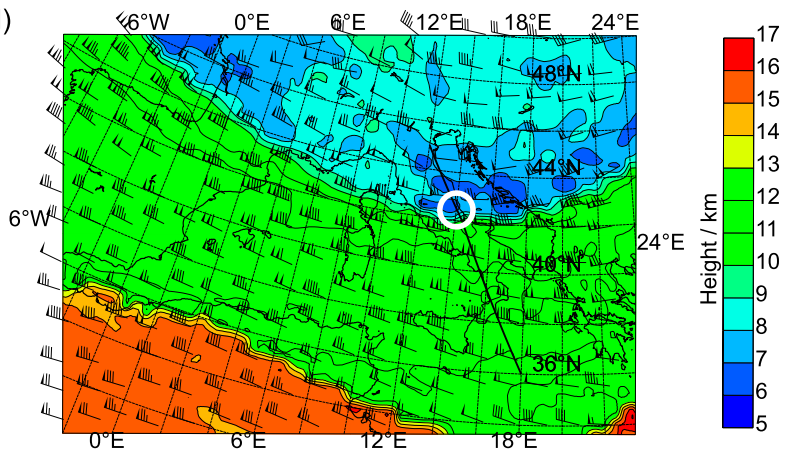

f)

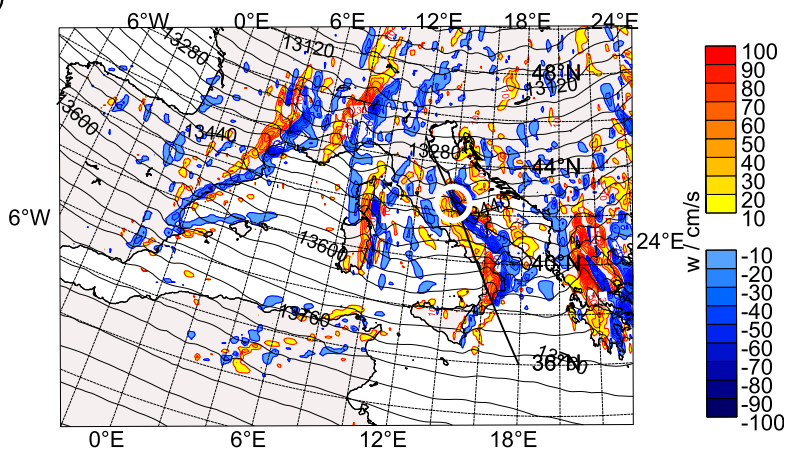

FIG. 3. (a),(b) IFS cycle $41 \mathrm{r} 2$ analyses of the mean sea level pressure (hPa; black lines) and the 10-m horizontal wind ( $\mathrm{m} \mathrm{s}^{-1}$; barbs), (c), (d) height of the dynamical tropopause ( $\mathrm{km}$; color shading) and the horizontal wind at the tropopause $\left(\mathrm{cm} \mathrm{s}^{-1}\right.$; barbs), and (e), (f) the vertical wind $\left(\mathrm{cm} \mathrm{s}^{-1}\right.$; color shading) and geopotential height (m; solid lines) at $150 \mathrm{hPa}$ valid for (left) 0600 and (right) $1200 \mathrm{UTC}$. The straight black lines show the flight track of HALO's transfer flight, and the circles indicate the position of the stall-warning event. Flight direction was from north to south.

to 1200 UTC. According to these high-resolution IFS analyses, HALO first encountered a downdraft related to the mountain waves. Farther south above the Apennines, it entered an updraft. Both wave encounters happened laterally with respect to the phase line of the mountain waves, that is, almost perpendicular to the mean wind.

To better understand the structure of the mountain waves, Figs. $5 \mathrm{a}$ and $5 \mathrm{~b}$ juxtapose vertical cross sections along $42^{\circ} \mathrm{N}$ and along the flight track. Both panels span the same vertical range. Figure 5a reveals hydrostatic mountain waves above Corsica and Italy: phase lines are located directly above the obstacles and extend from the troposphere to the stratosphere indicating vertical propagation for these mountain waves. The cross section in Fig. 5b shows adjacent down- and updrafts extending along HALO's flight track related to these mountain waves. 

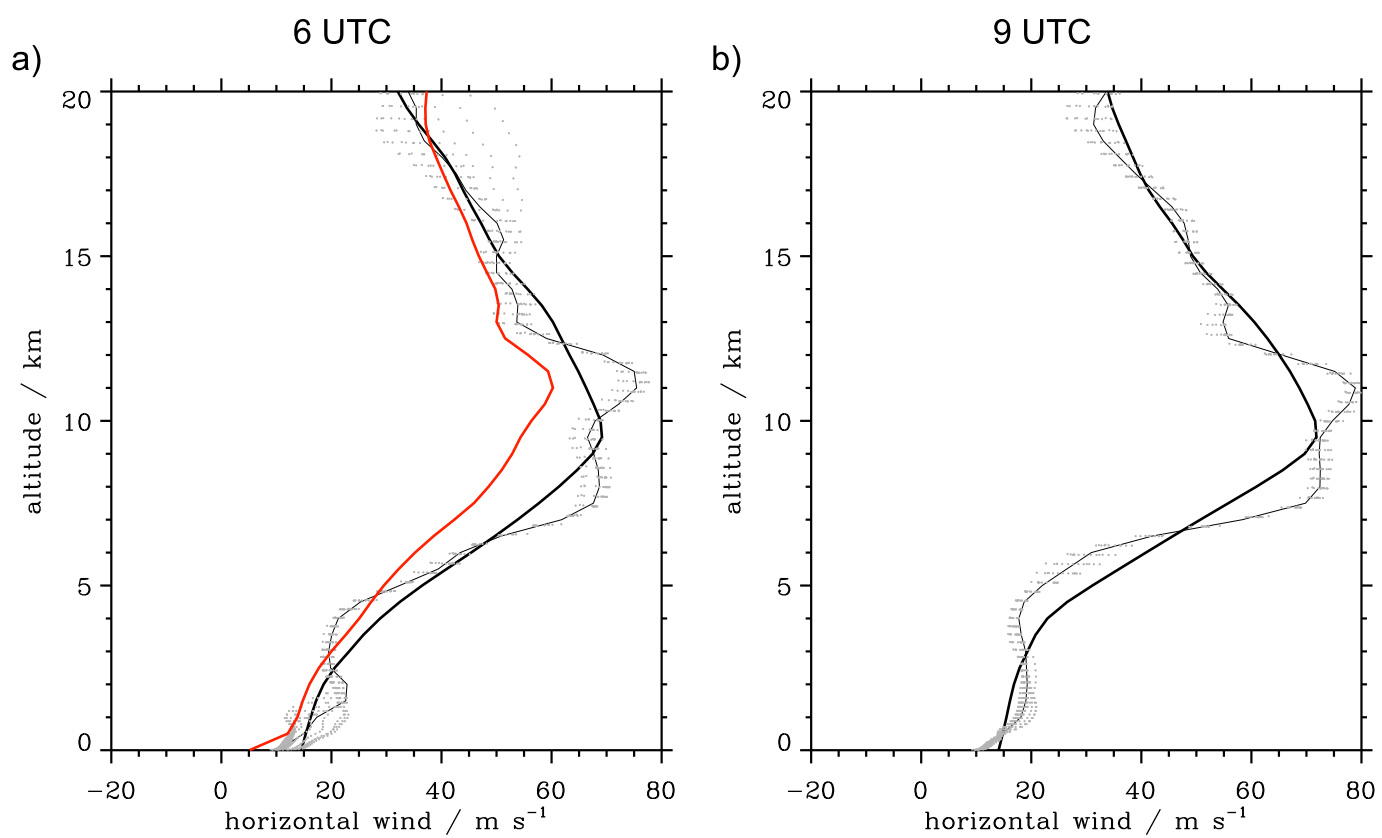

FIG. 4. Vertical profiles of the horizontal wind speed at $42^{\circ} \mathrm{N}$ for (a) 0600 and (b) 0900 UTC from IFS cycle 41r2 forecasts. Thin lines are calculated on the $500-\mathrm{m}$ vertical grid points, and thick lines are the vertical mean over a $10-\mathrm{km}$ boxcar average. The gray dots show the variability between $10^{\circ}$ and $11.5^{\circ} \mathrm{E}$. The red profile at $0600 \mathrm{UTC}$ shows the T21 profile calculated on the 500-m vertical grid points used to initialize EULAG.

Temporal and spatial interpolation to the flight track reveals that the temperature decreased gradually from about 213 to $210 \mathrm{~K}$ during the stall-warning event (see Fig. 7, below). Also, the meridional wind speed decreased by about $9 \mathrm{~m} \mathrm{~s}^{-1}$ and, in addition, changed its direction from a southerly to northerly direction.

Analysis of the Scorer parameter indicates that gravity waves with horizontal wavelengths $\lambda_{h}$ of larger than approximately $25 \mathrm{~km}$ at $42^{\circ} \mathrm{N}$ are able to propagate freely through the troposphere up to the lower stratosphere (Fig. 6). Farther to the south at $40^{\circ} \mathrm{N}, \lambda_{h}$ increases and only gravity waves with scales larger than $29 \mathrm{~km}$ are nonresonant. The vertical profiles of the Scorer parameter further suggest that gravity waves with $18 \lesssim \lambda_{h} \lesssim$ $29 \mathrm{~km}$ are trapped in a layer between $6-$ and $12-\mathrm{km}$ altitude. All gravity waves with $\lambda_{h}<18 \mathrm{~km}$ seem to be evanescent in the troposphere and should not be able to reach the tropopause. Between 0600 and 0900 UTC, the background conditions for gravity wave propagation remain steady (not shown).

The polar front jet is not only a favorable guide for the vertical propagation of the mountain waves, upper-level fronts are also regions known to generate turbulence because of the strong vertical shear of horizontal wind (Dutton 1969; Delay and Dutton 1971; Kennedy and Shapiro 1975; Shapiro 1976). Therefore, the position of HALO's flight track relative to the polar front jet is depicted by a vertical cross section along the flight track (Fig. 5c). With a flight altitude of about $12 \mathrm{~km}$, HALO was well above the jet streak of the polar front jet and also outside the regions containing the largest vertical shear. Pilot reports about merely light turbulence are a further indication that HALO was outside the regions of CAT generation related to upper-level fronts.

\section{Mountain wave characteristics}

Knowing the meteorological situation, we can attribute the regular shape of the up- and downdrafts in the in situ wind measurements to the mountain wave activity above the Apennines (Fig. 7). Strong gradients are present in all parameters in the area of the stall-warning event (gray shading in Fig. 7). In this region, peak-topeak amplitudes in the measured vertical wind reach $4 \mathrm{~m} \mathrm{~s}^{-1}$ and in the meridional wind up to about $23 \mathrm{~m} \mathrm{~s}^{-1}$. Also, the temperature measurement reveals pronounced peak-to-peak amplitudes with values up to $9 \mathrm{~K}$ during the stall-warning event. Analysis of the phase relations, especially of the vertical wind and temperature in the area of the stall-warning event, reveals that these are not perfectly following linear wave theory. In this area, the larger-scale pattern of the vertical wind is superimposed by small-scale structures. This might be due to turbulence induced by nonlinear processes, for 
a)

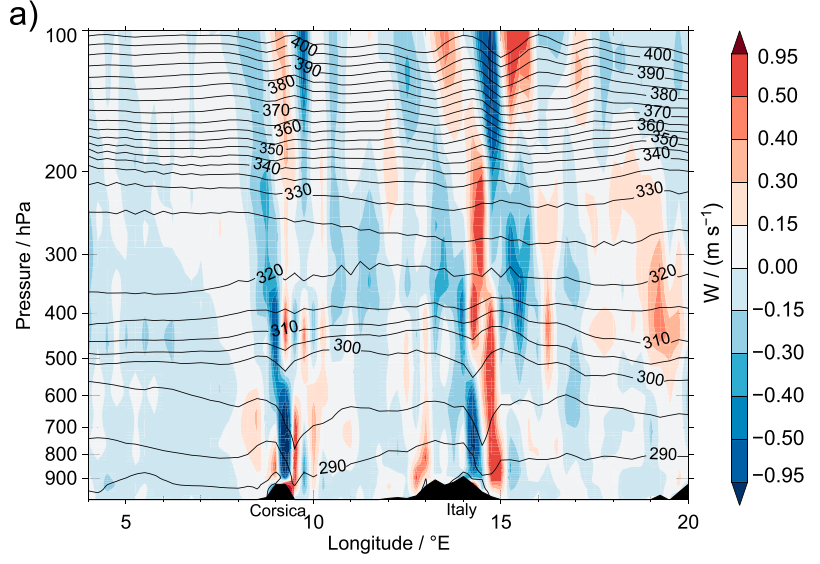

b)

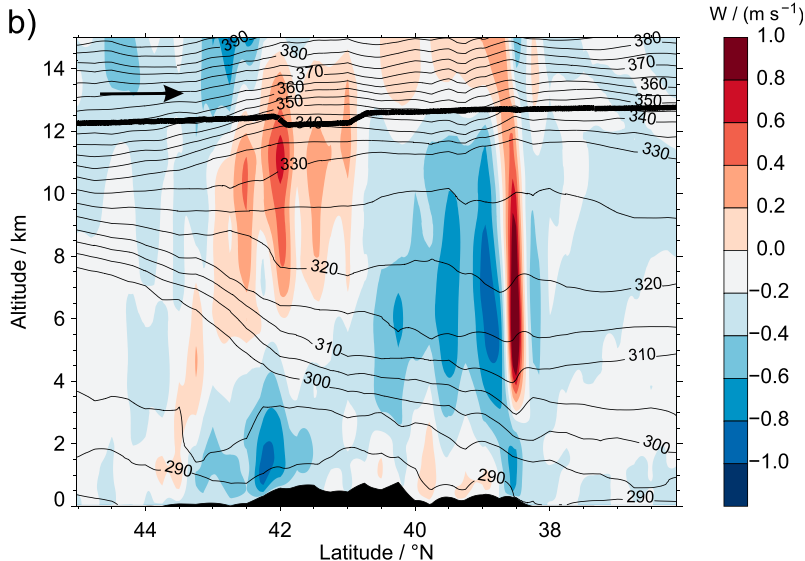

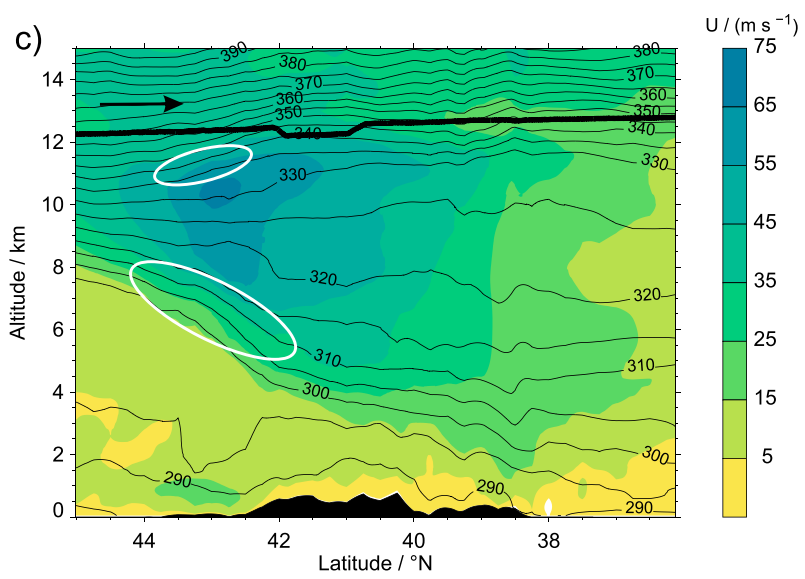

FIG. 5. Vertical cross sections of the (a) vertical wind along $42^{\circ} \mathrm{N}$, (b) vertical wind, and (c) horizontal wind along the flight track. The white circles in (c) highlight the regions with the largest vertical shear. The thin black contour lines are the isentropic surfaces (K) with an increment of $5 \mathrm{~K}$, and the black-shaded regions correspond to the surface terrain. The thick black line in (b) and (c) shows HALO's flight track, and the black arrow indicates the flight direction. The plot in (a) is valid at 1200 UTC, and the data in (b) and (c) were interpolated both in time and horizontal space to the flight track.

example, by breaking mountain waves. South of the stall-warning event, observed amplitudes are less pronounced in all parameters when HALO was flying almost along the phase lines of the mountain waves. Between $39^{\circ}$ and $38^{\circ} \mathrm{N}$, increased, isolated peaks are again revealed in all parameters, with peak-to-peak amplitudes up to about $6 \mathrm{~K}$ in the temperature and $10 \mathrm{~m} \mathrm{~s}^{-1}$ in the meridional and zonal wind component, respectively. In the vertical wind, peak-to-peak amplitudes of up to $4 \mathrm{~m} \mathrm{~s}^{-1}$ were observed.

The IFS data interpolated in time and space to the flight track reproduce the large-scale pattern along the flight track very well in all observed parameters. However, the small-scale structures and the sharp spatial gradients, especially in the stall-event area, were not captured by the IFS. This discrepancy indicates that the IFS underestimates the amplitudes and horizontal wavelengths of the vertically propagating mountain waves.
An analysis of the vertical energy flux $\mathrm{EF}_{z}$ based on the in situ measurements along the flight track south of the stall-warning event reveals upward propagating mountain waves with a local maximum of $18.1 \mathrm{~W} \mathrm{~m}^{-2}$ and a leg-integrated value of $\mathrm{EF}_{z} \approx 8 \mathrm{~W} \mathrm{~m}^{-2}$ (Fig. 8a). The wavelet analysis of $\mathrm{EF}_{z}$ shows that the horizontal scales $\lambda_{h}$ of the dominant flux-carrying waves range between 20 and about $65 \mathrm{~km}$ (Fig. 8b). Consistent with the upward energy transport and thus the Eliassen-Palm relation [Eq. (3)], the energy flux calculated by the scalar product of horizontal wind and the momentum fluxes is mostly negative, with a minimum value of $-23.3 \mathrm{~W} \mathrm{~m}^{-2}$ and a leg-integrated value of $-2.3 \mathrm{Wm}^{-2}$ (Fig. 8a). Because the ambient horizontal wind is mainly zonally oriented, we present the spectral analysis of the zonal momentum flux $\mathrm{MF}_{x}$. Horizontal wavelengths for the dominant fluxes range from $\lambda_{h} \approx 30$ to about $65 \mathrm{~km}$ (Fig. 8c) in agreement with predictions of the Scorer parameter and are associated with westward 
a)

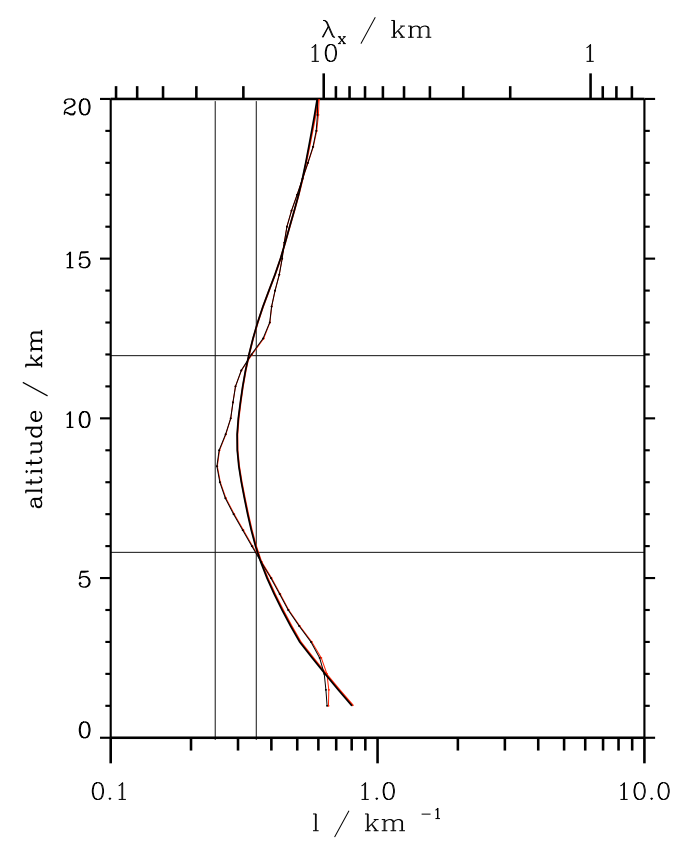

b)

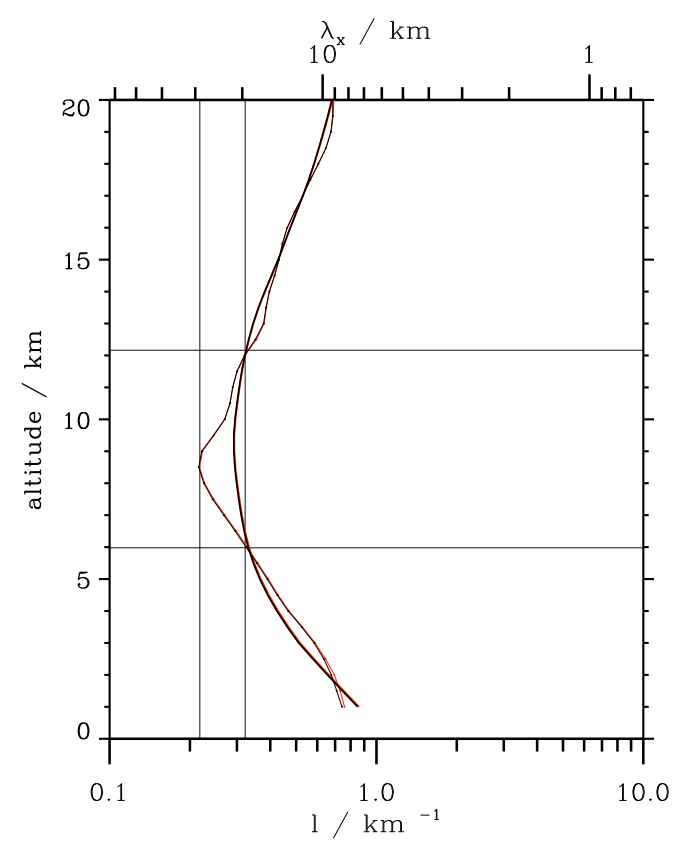

FIG. 6. Vertical profiles of the Scorer parameter as based on ECMWF T21 forecasts at (a) $42^{\circ} \mathrm{N}$ and (b) $40^{\circ} \mathrm{N}$ for 0900 UTC. Thin lines with dots are calculated on the 500-m vertical grid points, and thick lines are the vertical mean over a 10-km boxcar average. Red profiles are calculated with the zonal wind component $u$ only, and the black profile is calculated with the horizontal wind $U\left[=\left(u^{2}+v^{2}\right)^{1 / 2}\right]$.

(negative) zonal momentum fluxes. To oppose strong downwind advection by the mean ambient flow, mountain waves need to propagate upwind through the atmosphere (Smith et al. 2016). Our analysis reveals this horizontal upwind propagation with the negative zonal momentum fluxes, thus suggesting westward-propagating mountain waves that are balancing the mean flow.

To check if the observed mountain waves at flight level can be described by linear theory, the EliassenPalm relation [Eq. (3)] is applied. The subleg-integrated fluxes of both the $\mathrm{EF}_{z}$ and $\mathrm{EF}_{z M}$ are qualitatively well anticorrelated for the portion of the flight leg south of the stall-warning event (starting at $40.7^{\circ} \mathrm{N}$ in Fig. $8 \mathrm{a}$ ). However, between $40.7^{\circ}$ and $38.5^{\circ} \mathrm{N}$ magnitudes of $\mathrm{EF}_{z}$ and $\mathrm{EF}_{z M}$ differ up to about $4 \mathrm{~W} \mathrm{~m}^{-2}$ in the mean. For the leg-integrated fluxes, the anticorrelation is off by a factor of 3.5. That way, both the subleg-integrated and the leg-integrated fluxes point to either wave trapping or nonlinear processes, for example, as wave breaking. Furthermore, the spectral analysis (Figs. 8b,c) reveals that the anticorrelation of the fluxes according to the Eliassen-Palm relation is only valid for horizontal wavelengths $\lambda_{h} \geqslant 30 \mathrm{~km}$ implying again that modes with $\lambda_{h}<30 \mathrm{~km}$ are either trapped or involved in nonlinear processes.

\section{Turbulence measurements and forecasts}

\section{a. In situ turbulence analysis}

Along-track profiles of TKE derived from in situ wind measurements as described in section 2 are shown in Fig. 9a. Here, we show TKE calculated for sublegs ranging between 20 and $4 \mathrm{~km}$ to analyze how much of the variances due to mesoscale motions have been removed by assuming a $4-\mathrm{km}$ window. As expected, the TKE contained in larger scales (subleg length of $\approx 20 \mathrm{~km})$ is greater than in the smaller scales $(4 \mathrm{~km})$. Furthermore, the small difference in TKE values of $0.03 \mathrm{~m}^{2} \mathrm{~s}^{-2}$ between the 8 - and 4-km subleg lengths (in the gray-shaded part) suggests that the largest contributions to the variance due to mesoscale perturbations are removed around this scale. Here, we perform the turbulence analysis with the $4-\mathrm{km}$ subleg lengths because we are mostly interested in turbulent scales between about $300 \mathrm{~m}$ and $1 \mathrm{~km}$, which affect aircraft the most (MacCready 1964; Vinnichenko et al. 1980; Hoblit 1988; Sharman et al. 2014).

In the northern part of the leg and before the stall events, almost no TKE is contained in the 4-km subleg lengths. Farther south, TKE values increased to about $0.35 \mathrm{~m}^{2} \mathrm{~s}^{-2}$ when HALO entered the region of the stallwarning event (gray-shaded area in Fig. 9a). South of the 

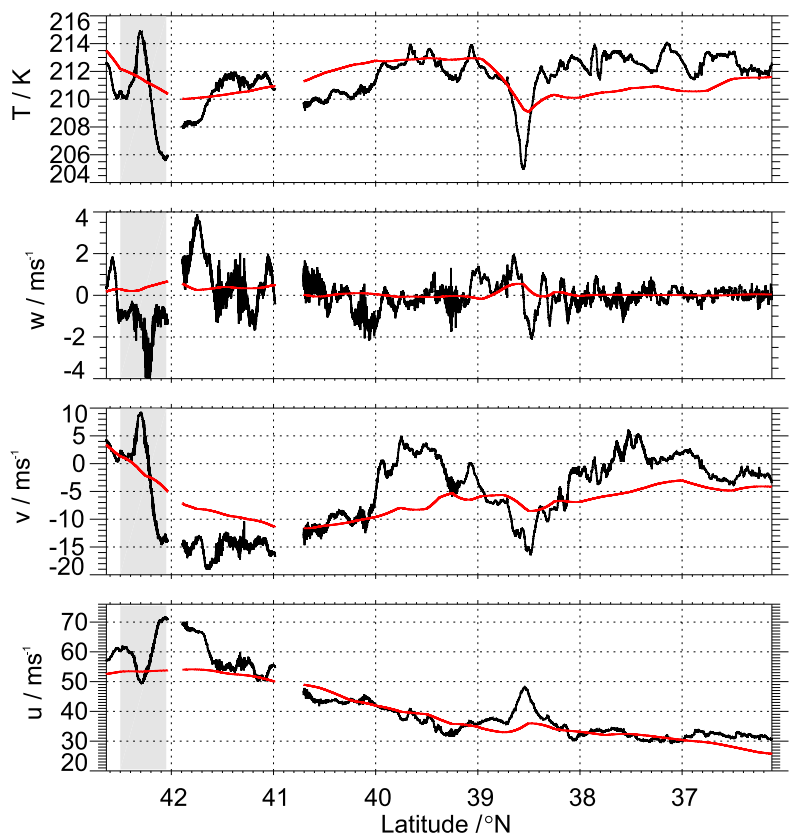

FIG. 7. In situ measurements (black) and IFS cycle 41r2 forecasts (red) of (top) temperature, (top middle) vertical wind, (bottom middle) meridional wind, and (bottom) zonal wind. IFS forecasts have been interpolated both in time and space to the flight track. The gray shading highlights the area of the stall-warning event, and the gaps are related to the altitude changes resulting from the stallwarning event.

stall-warning event, TKE values increased little up to $0.4 \mathrm{~m}^{2} \mathrm{~s}^{-2}$ and decreased afterward. These TKE values are smaller than the nominal threshold value of $0.6 \mathrm{~m}^{2} \mathrm{~s}^{-2}$ used by Strauss et al. (2015) to indicate light turbulence.

Furthermore, the inspection of the $\mathrm{EDR}_{i}$ profiles (calculated from in situ measurements) for 4-km subleg lengths reveals a similar structure as the TKE profile shown above: almost no turbulence in the northern part of the leg and increasing turbulence in the updraft region of the mountain wave and within the elongated mesoscale temperature anomaly (Fig. 9b). The individual $\mathrm{EDR}_{i}$ values show scatter around the log-mean $\overline{\mathrm{EDR}}$ that could come from, for example, anisotropic turbulence due to stratification of the atmosphere or uncertainties due to deviations from the $-5 / 3$ Kolmogorov slope. In contrast to Strauss et al. (2015), our analysis reveals that the transverse $\mathrm{EDR}_{v_{\mathrm{ac}}}$ component is, in the mean, larger by a factor of 1.3 than the longitudinal $\mathrm{EDR}_{u_{\mathrm{ac}}}$. Overall, in accordance with the small TKE values the computed EDR values indicate only light turbulence during this flight segment confirming the pilot reports.

\section{b. Turbulence forecast}

For our study turbulence forecasts of the GTG are compared to the in situ aircraft data. To be consistent with previous studies (e.g., Sharman et al. 2014; Sharman and Pearson 2017), only the EDR derived from vertical wind measurements is taken into account. Moreover, as seen in Fig. 9b, the $\mathrm{EDR}_{w}$ values mostly fall in the same turbulence category as the $\overline{\mathrm{EDR}}$.

Above Italy, the GTG predicts light to moderate turbulence connected to the strong polar front jet and mountain wave activity (Figs. 10a,b). In particular, in the region of the stall-warning event moderate turbulence is forecast. Relative to the in situ measured EDR, the forecast EDR values are higher (see Fig. 10c) and the spatial structure is less intermittent. The mean difference between the EDR for CAT only and the measured EDR is, at $0.14 \mathrm{~m}^{2 / 3} \mathrm{~s}^{-1}$, slightly larger than the mean difference between EDR for MWT and the measured EDR of $0.13 \mathrm{~m}^{2 / 3} \mathrm{~s}^{-1}$. This result reflects the tendency of overpredicting by the GTG as was also found in Sharman and Pearson (2017). However, particularly above southern Italy, the measured EDRs are mostly in the same turbulence-severity category (light) as the predicted EDRs.

\section{High-resolution numerical simulations}

Simulations with the nonhydrostatic model EULAG are used to study the magnitude of mountain waveinduced gradients in the region of the stall-warning event. These simulations reveal coherent, stationary structures in the perturbations of the potential temperature as well as the meridional and vertical wind fields above Italy (Figs. 11a-c). The simulations also indicate that mountain waves with larger horizontal wavelengths dominate the meridional wind and temperature perturbations, while smaller-scale mountain waves prevail in the vertical wind. Amplitudes in the meridional wind field are about $9 \mathrm{~m} \mathrm{~s}^{-1}$; amplitudes are about $4 \mathrm{~m} \mathrm{~s}^{-1}$ in the vertical wind speed. The perturbations of the potential temperature reach values of up to $7 \mathrm{~K}$.

In the region of the stall-warning event (Fig. 11, black circle), short-scale fluctuations with large amplitudes are present in all three parameters. The profiles in Fig. 12 show a decrease in the meridional wind speed from about 10 to $-8 \mathrm{~m} \mathrm{~s}^{-1}$ within a horizontal distance of approximately $40 \mathrm{~km}$ at the altitude range of the flight track. The distance between the maximum and minimum values in the meridional direction is larger by about $10 \mathrm{~km}$ relative to the observations. The peak-topeak amplitude, on the other hand, is, at $18 \mathrm{~m} \mathrm{~s}^{-1}$, slightly smaller than the observed one of about $23 \mathrm{~m} \mathrm{~s}^{-1}$ but higher than the amplitude provided by the IFS forecasts. The potential temperature decreases in the same area by about $10 \mathrm{~K}$. 
a)

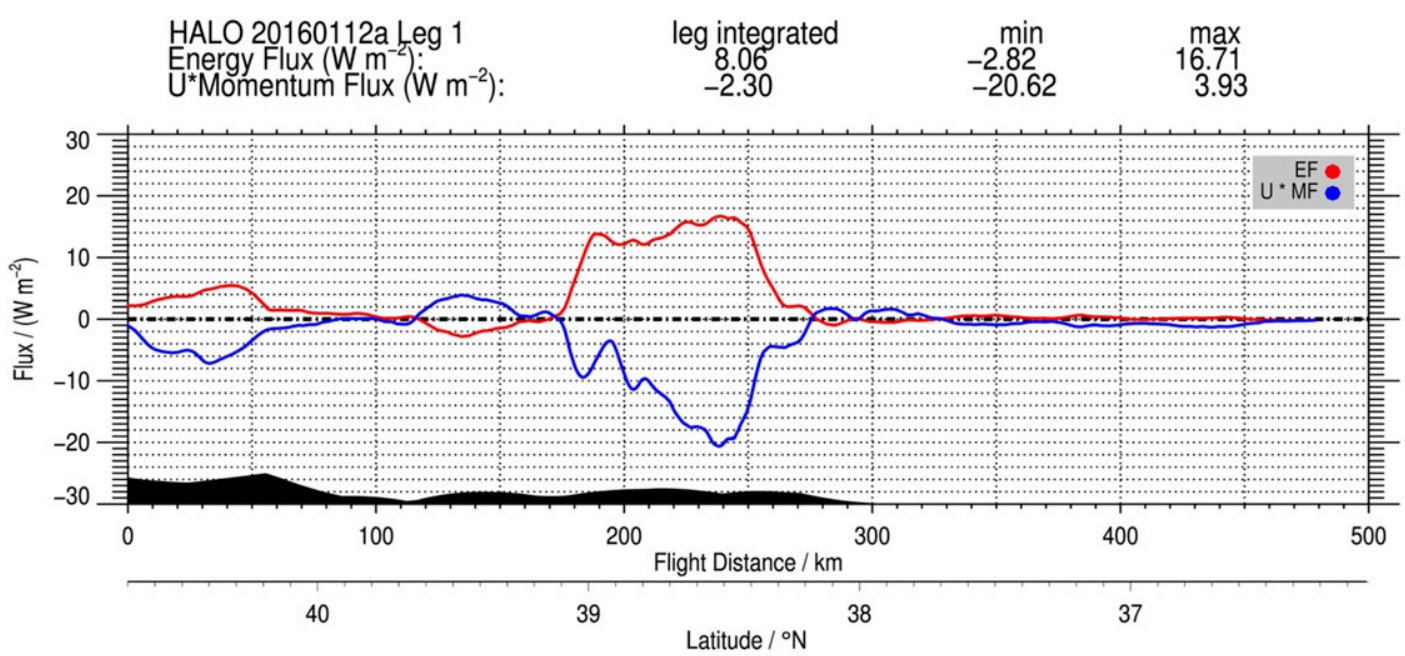

b)
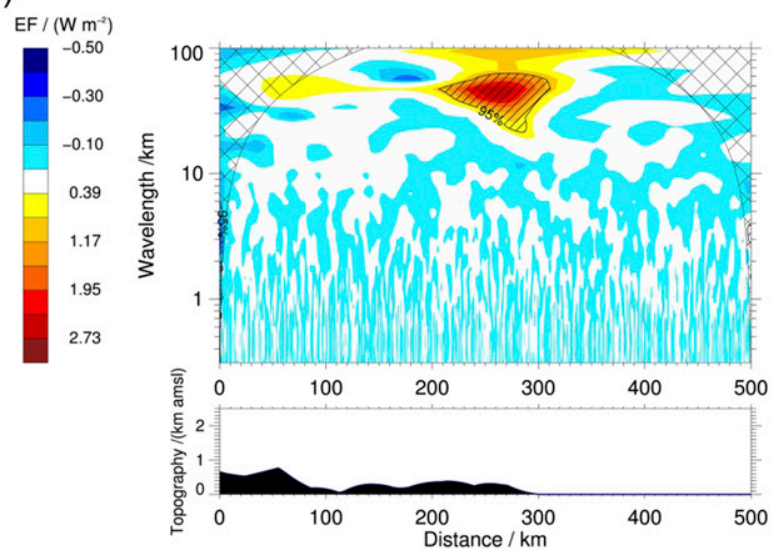

C)

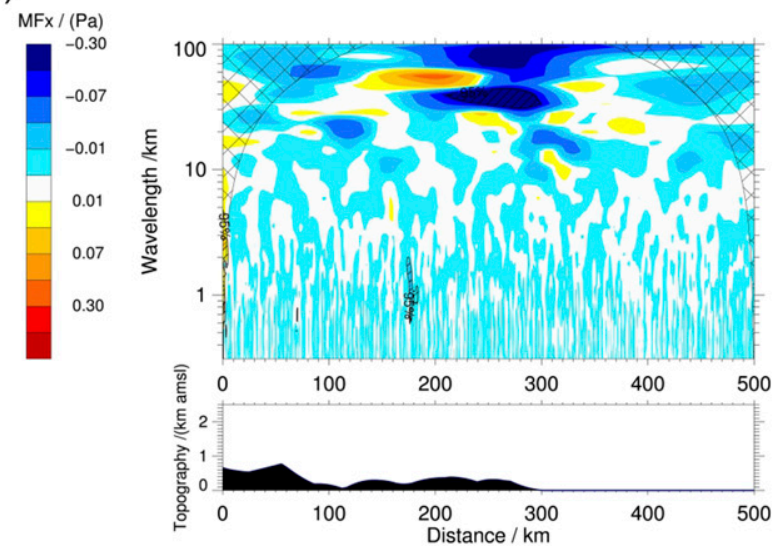

FIG. 8. (a) Subleg-integrated vertical energy flux (red) and subleg-integrated energy flux derived from horizontal momentum fluxes (blue) along the flight leg after the stall-warning event. Also shown are cospectra of (b) vertical energy flux $\mathrm{EF}_{z}$ and (c) zonal momentum flux $\mathrm{MF}_{x}$ along the same leg segment.

Enhanced TKE (Fig. 11d) suggests partial breaking of smaller-scale mountain waves above Italy.

\section{Discussion and conclusions}

This case study reveals that mountain wave-induced variations of ambient along-track wind and temperature were responsible for the initiation of the stallwarning event encountered by the research aircraft HALO. With knowledge of atmospheric background conditions, it was possible to reconstruct the aircraft's behavior and the reactions of the autopilot system.

Strong northwesterly surface flow excited vertically propagating mountain waves above the Apennines. Because of the zonal alignment of the polar front jet with the low-level winds, these mountain waves could propagate vertically into the stratosphere without significant dissipation and attained large amplitudes at FL410. Mountain wave-induced meridional wind perturbations with comparable amplitudes in highresolution EULAG simulations occur in the same area as the observed ones. The associated decrease of meridional wind by about $23 \mathrm{~m} \mathrm{~s}^{-1}$ (as seen in in situ data) translated into a loss of about $0.1 \mathrm{Ma}$ in aircraft speed. At this time, HALO flew in the stratosphere at about $12.5-\mathrm{km}$ altitude, an altitude region where the margin to the stall speed in the coffin corner is small. Although the decreasing temperature increased the density and thus the lift and thrust of the aircraft, this change was not large enough to compensate the effect of the along-track wind component on aircraft speed. Therefore, the deceleration of the aircraft through the sudden and strong change in the along-track wind reduced the margin to the stall speed making it necessary to accelerate the aircraft by means of full 

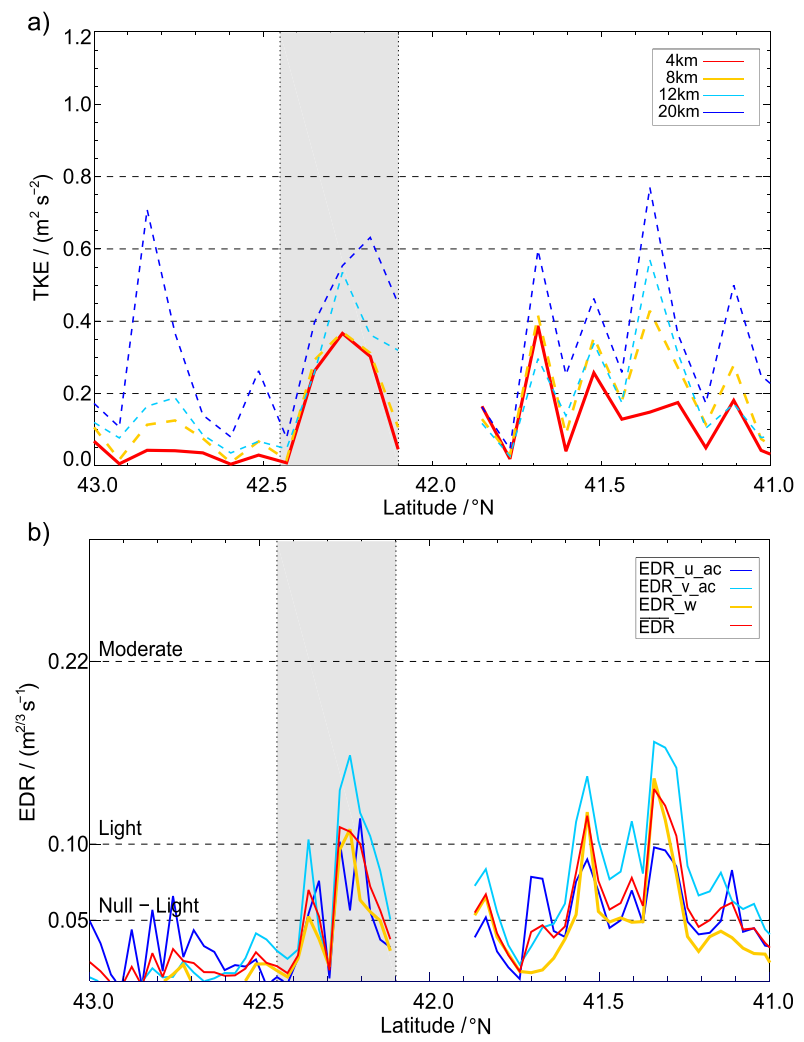

FIG. 9. (a) TKE calculated for different subleg lengths. (b) EDR for the three wind components and the logarithmic mean of all wind components $(\overline{\mathrm{EDR}})$. The shading highlights the area of the stall-warning event, and the gap in the data is related to the descent after the stall-warning event.

engine thrust and increased angle of attack. However, engine thrust is limited by the generally rather low air density at these altitudes and several stall warnings occurred. A descent to a lower flight level was the only measure to regain stable flight conditions.

In general, high-resolution IFS forecasts reproduce the large-scale flow in the vicinity of the observations, especially in the meridional wind speed and the temperature (Fig. 7). However, the observed perturbations in all presented parameters could not be reproduced in the area of the stall-warning event because of inadequate resolution. Therefore, the forecasts also underestimate the gradients in this region compared to the measured ones by $\sim 18 \%$ of the observation for the temperature and by $\sim 6 \%$ of the meridional wind. That way, the comparison suggests that large-scale structures, as, for example, an upper-level front, resolved in the IFS are not the dominant source of the observed strong gradients during the stall-warning event. Their largest gradients occurred at lower altitudes. High-resolution numerical simulations with EULAG, on the other hand, could reproduce the reversal of the direction and the decrease of the meridional wind speed with a similar magnitude as the observations. Therefore, we attribute the observed changes in ambient atmospheric conditions leading to the stall-warning event mainly to vertically propagating mountain waves above the Apennines.

The presence of significant mountain wave activity is established by large leg-averaged vertical energy flux of $\mathrm{EF}_{z} \approx 8 \mathrm{~W} \mathrm{~m}^{-2}$ derived from the high-quality in situ measurements of HALO. During the DEEPWAVE campaign, only 4 of 26 research flights at stratospheric altitudes show $\mathrm{EF}_{z}$ values exceeding $5 \mathrm{~W} \mathrm{~m}^{-2}$ (Smith et al. 2016). During the GW-LCYCLE I campaign, Wagner et al. (2017) found only one leg with $\mathrm{EF}_{z}>5 \mathrm{~W} \mathrm{~m}^{-2}$. The majority of the flux-carrying horizontal wavelengths approximately range between $\lambda_{h} \approx 20$ and $65 \mathrm{~km}$. Interestingly, this range lies in the intermediate scale [as defined by Smith et al. (2016)], which was the dominant scale in strong mountain wave cases during the DEEPWAVE campaign (Smith et al. 2016). Hence, the comparison with former gravity wave campaigns such as DEEPWAVE and GW-LCYCLE I suggests that the encountered mountain wave event on 12 January 2016 was an unusually strong event.

For $\lambda_{h}>30 \mathrm{~km}$, the Scorer parameter indicates freely propagating mountain waves and a nearly linear character can be attributed to those waves as, additionally, the Eliassen-Palm relation is fulfilled in these scales. It was the favorable zonal alignment of the low-level forcing to the waveguide of the polar front jet that was responsible for the nearly linear vertical wave propagation.

However, our mountain wave analysis indicates that not all wave modes propagated without dissipation through the atmosphere. In particular, the Scorer parameter suggests that waves with $\lambda_{h} \lesssim 29 \mathrm{~km}$ are either trapped or evanescent (Fig. 6). This contributes to the fact that the Eliassen-Palm relation is not completely fulfilled for leg-averaged fluxes. The scale analysis additionally points at either trapped or partially breaking mountain waves by showing anticorrelated fluxes only for $\lambda_{h}>30 \mathrm{~km}$. In the in situ measurements, the vertical wind speed particularly is superimposed by small-scale structures. Together with the production of TKE in the EULAG simulations, the observations indicate the presence of turbulence. The GTG forecasts moderate turbulence with regard to both CAT and MWT, but with slightly larger EDR values for the MWT in the region of the stall-warning event. As HALO's flight track was located outside the region of strongest shear in the polar front jet and the TKE in EULAG is related to nonlinear 
a) CAT

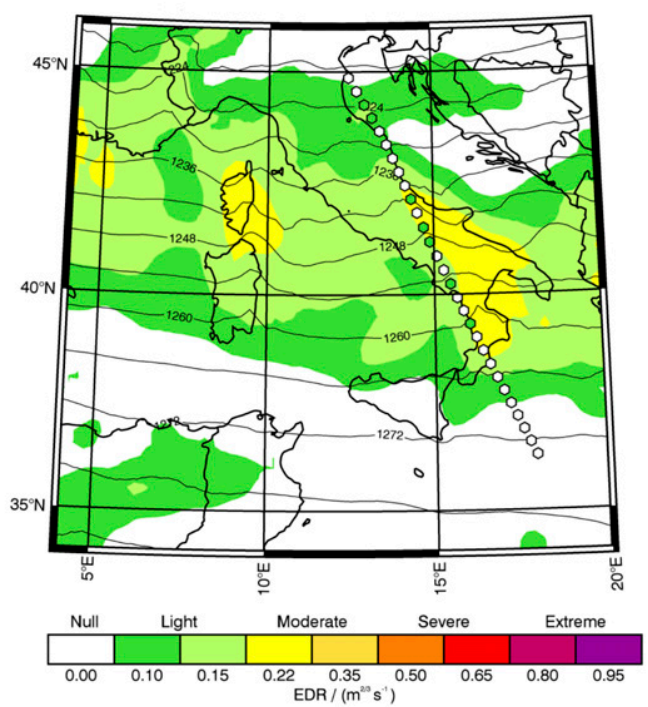

b) MWT

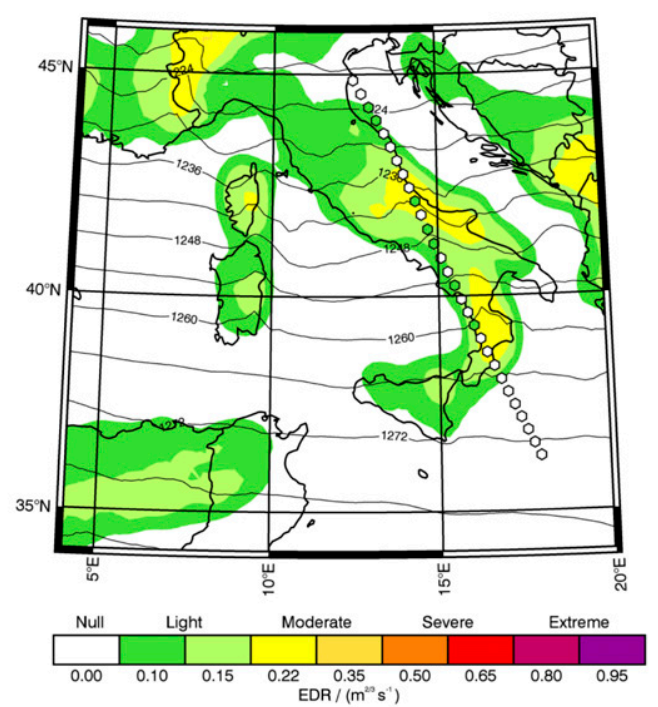

c)

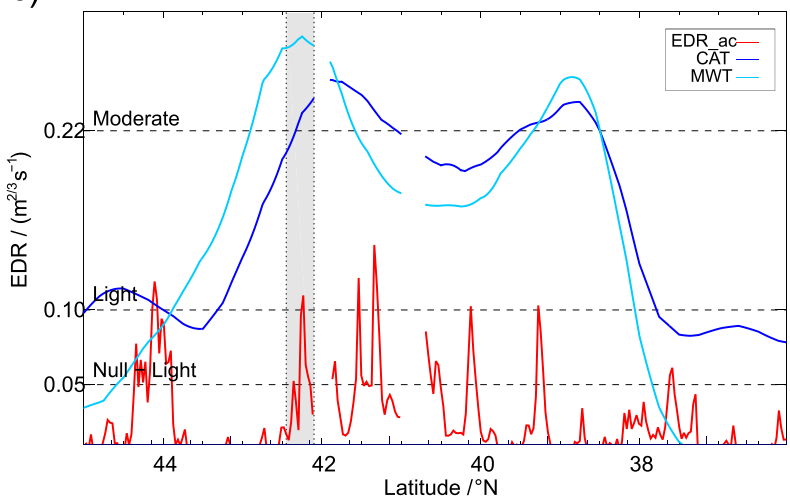

FIG. 10. GTG turbulence forecasts for (a) CAT and (b) MWT at FL410 together with the geopotential height (m; black solid lines). The line of circles shows the color-coded severity of turbulence resulting from the maximum value over 10 EDRs calculated from in situ vertical wind measurements along the flight leg. Also shown is (c) a comparison of EDR derived from vertical wind measurements and GTG forecasts interpolated to the flight track in space and time along the flight leg.

processes in the mountain wave field, we attribute the observed light turbulence to breaking mountain waves or other small-scale instabilities.

Because of the processes described above, our case study reveals that stratospheric mountain waves pose a serious hazard, in particular to modern, highflying aircraft. The mountain waves generate mesoscale stratospheric horizontal wind and temperature anomalies resulting in large horizontal gradients of these parameters. If aircraft fly through them, they encounter a sequence of accelerating and decelerating anomalies. Depending on its type, the aircraft's speed changes as a result of the modulation of the horizontal wind field, and incidents such as the one described in this study might occur. So far, turbulence is considered to be among the major hazards for commercial air traffic flying between 8 - and $14-\mathrm{km}$ altitudes (e.g., Lane et al. 2009; Sharman et al. 2012b; Williams 2017). Therefore, it is only natural to draw the attention to breaking mountain waves and their induced turbulence. Thus, for example, in a former field campaign the flight planning for the ER-2 aircraft focused on the forecast of mountain wave turbulence, which means whenever laminar mountain waves were present, the aircraft was allowed to fly (Eckermann et al. 2006). Yet, the present study shows that turbulence did not play a major role in the creation of the strong horizontal meridional wind and temperature gradients leading to the stall warnings but was instead entirely attributable to vertically propagating near-laminar mountain wave oscillations alone. This is an important aspect for flight planning especially of 
a)

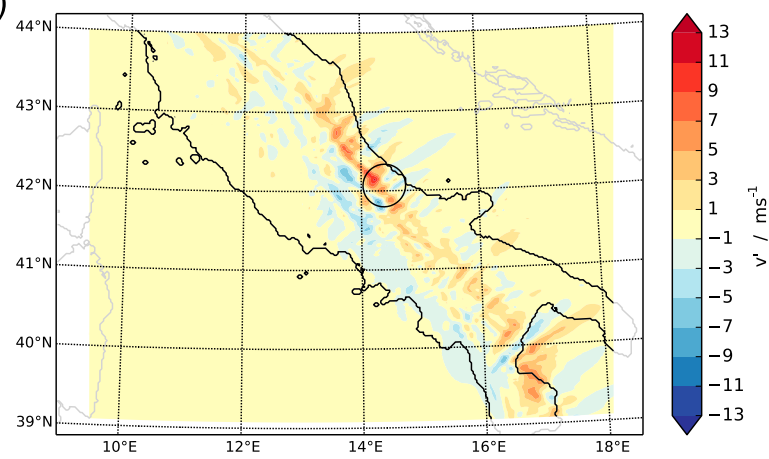

c)

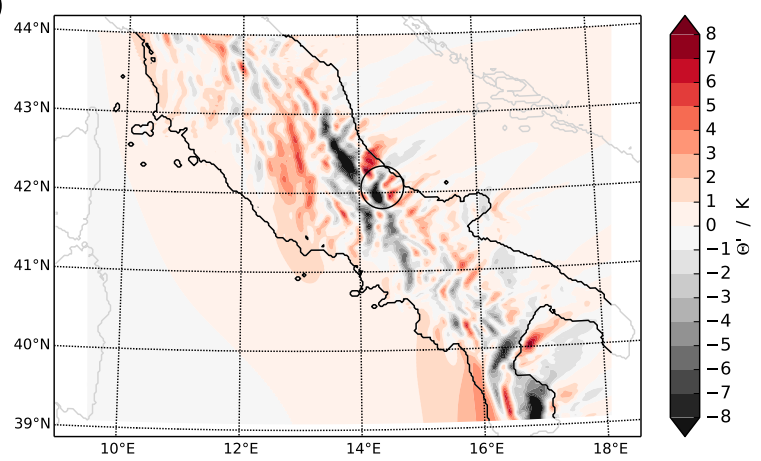

b)

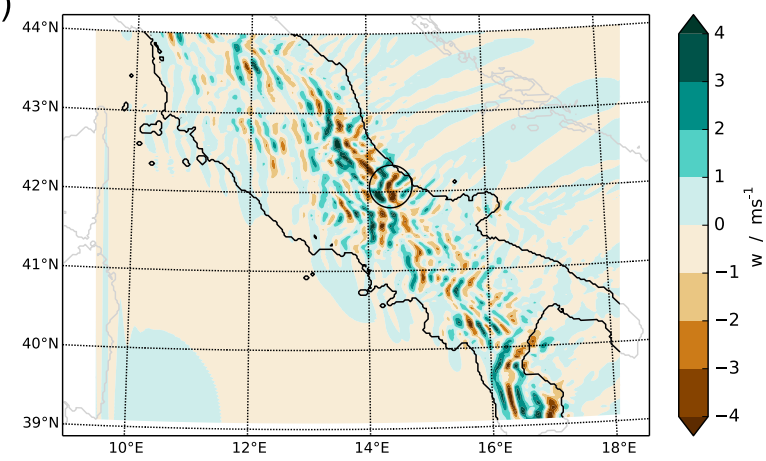

d)

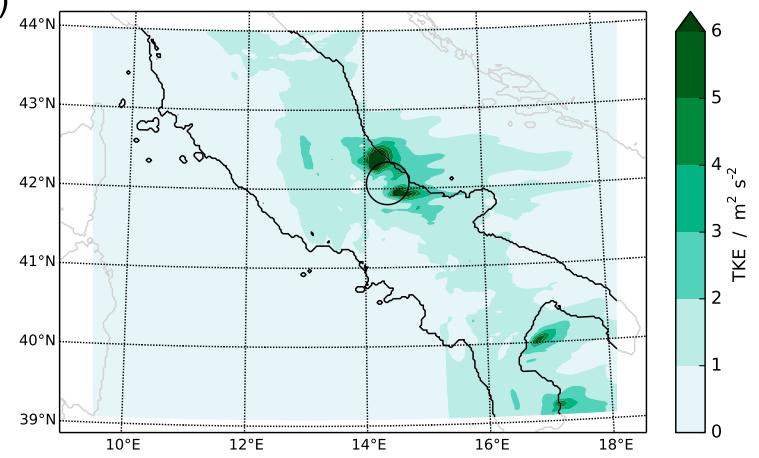

FIG. 11. (a) Meridional wind perturbations, (b) vertical wind, (c) temperature perturbations, and (d) TKE as simulated by EULAG at $12.5-\mathrm{km}$ altitude. The black circle indicates the position of the stall-warning event with a radius of $30 \mathrm{~km}$.

high-flying aircraft such as, for example, the ER-2 or the Global Hawk.

Accumulated anecdotal experience of Swiss International Airlines AG ("SWISS") pilots F. Fusina and $\mathrm{M}$. Gerber suggests that encounters such as the one described in this study are not uncommon above mountainous terrain. At higher altitudes $(\approx 20 \mathrm{~km})$, encounters with propagating mountain waves were also reported by the ER-2 aircraft and caused, for example, vertical displacements of about $1.5 \mathrm{~km}$ (Bacmeister et al. 1990; Chan et al. 1993; Leutbecher and Volkert 2000). However, because of its design, the ER-2 is highly susceptible to changes in the ambient atmosphere. Today, the common flight level for commercial air traffic is at FL380, where the margin in the coffin corner is larger than in the analyzed event. With the projected increase in passenger numbers in the next 20 years (IATA 2017), however, flight-level altitudes might increase because of increased air traffic density. This, in turn, would, on the one hand, reduce the margin in the coffin corner for aircraft. On the other hand, an increase in mountain wave amplitudes can be expected because of the decreasing density with altitude, which could lead to stronger gradients in temperature or the horizontal wind and thus stronger effects on an aircraft flying at FL430 than on one flying at FL380. Because global flight routes such as, for example, the North Atlantic tracks, often lead across mountainous terrain, we suggest including information on propagating mountain waves in the flightplanning process or in the significant-weather charts.

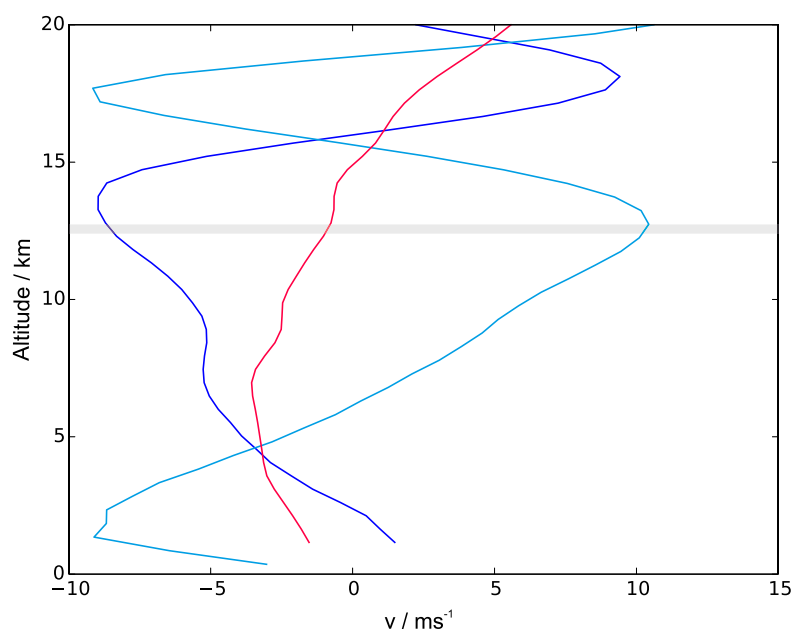

FIG. 12. Vertical profiles of the meridional wind at the positions of the maximum or minimum meridional wind perturbation within the black circle shown in Fig. 11 (blue lines). The red line shows the background meridional wind profile, and the gray shading highlights the altitude of the flight track. The spatial horizontal distance between the blue profiles is about $40 \mathrm{~km}$. 
Acknowledgments. We especially thank Prof. Ulrich Schumann for detailed insights and tireless discussions about aerodynamics and aircraft control. We greatly appreciate his support to construct this study. We also thank three anonymous reviewers for insightful comments and suggestions that have contributed to improve this paper. Part of this research was funded by the German research initiative Role of the Middle Atmosphere in Climate (ROMIC/01LG1206A), funded by the German Ministry of Research and Education in the project Investigation of the life cycle of GWs (GW-LCYCLE), and by the Deutsche Forschungsgemeinschaft (DFG) via the project MS-GWaves (GW-TP/DO 1020/9-1, PACOG/RA 1400/6-1). Access to the ECMWF data was possible through the special project HALO Mission Support System.

\section{APPENDIX}

\section{Aircraft Dynamics}

\section{a. Flight envelope}

Figure A1 shows the principle schematic for a flight envelope for flight levels above FL250 for an aircraft such as a Boeing B767-300. In this altitude range, the stall speed and the maximum operation Ma converge in a region that pilots call the coffin corner.

\section{b. Aircraft speed at high altitudes-Mach number}

The ratio of aircraft speed and speed of sound is called Mach number, or Ma. At high altitudes and high aircraft speeds, the aircraft speed is expressed as fraction of Ma. For subsonic, compressible flow Ma is determined by

$$
\mathrm{Ma}=\left\{\frac{2}{\gamma-1}\left[\left(\frac{p_{0}-p_{s}}{p_{s}}+1\right)^{\frac{\gamma-1}{\gamma}}-1\right]\right\}^{1 / 2},
$$

where $\gamma$ is the ratio of specific heats, $p_{0}$ denotes the total pressure, and the static pressure is given by $p_{s}$ (Corda 2017). This equation shows that the aircraft speed is directly proportional to the relative speed between the aircraft and the horizontal wind speed $v$ in the direction along the aircraft via the compressible Bernoulli equation:

$$
p_{0}-p_{s}=\frac{1}{2} \rho v^{2}\left(\frac{\gamma-1}{\gamma}\right) \text {. }
$$

\section{c. Lift}

Airfoils generate lift as a result of the pressure difference between the airfoil's upper and lower surfaces. As the flow speed is increased on the upper surface, the

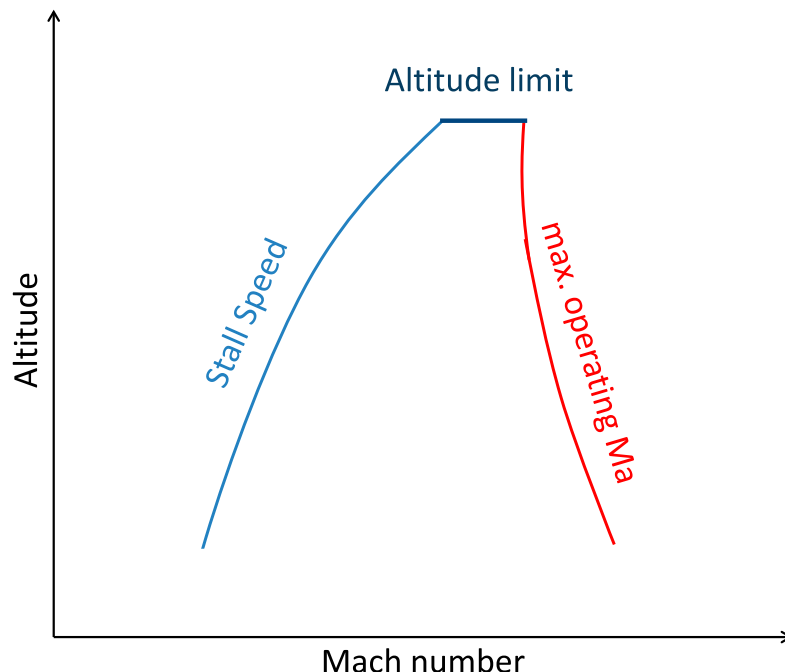

FIG. A1. Schematic flight envelope at flight levels that are higher than FL250.

static pressure reduces in this area and becomes lower than the pressure on the lower surface (Corda 2017). Lift $L$ can be calculated by

$$
L=0.5 \rho v^{2} C_{L} S,
$$

with the air density $\rho$, the lift coefficient $C_{L}$, freestream velocity $v$, and a reference area $S$.

\section{d. Thrust}

In principle, thrust is the force that moves an aircraft through the air and is used to overcome the drag of an airplane. It is a reaction force that can be described with Newton's second and third laws. An aircraft engine generates thrust by adding energy to a mass flow. When the mass flow exits the engine its velocity is higher than that of the flow entering at the inlet of the engine. As the air accelerates to the rear, the reaction force, thrust, is directed toward the front. The thrust Thr of an engine can be calculated with

$$
\mathrm{Thr}=\dot{m}\left(V_{e}-V_{\infty}\right)=\rho A V\left(V_{e}-V_{\infty}\right),
$$

where $V_{e}$ is the velocity of the exhaust, $V_{\infty}$ is the freestream velocity, and $\dot{m}$ determines the mass flow rate through the engine and can also be expressed by air density $\rho$, the area $A$, and the mass flow velocity $V$ (Brandt et al. 2004).

\section{e. Angle of attack}

The angle of attack $\alpha$ is the angle between the chord line of an airfoil and the freestream direction. Figure A2 visualizes the angle of attack of an airfoil. 


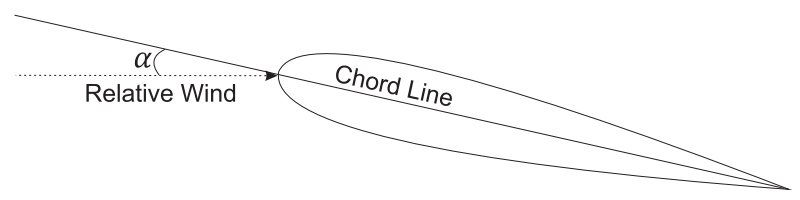

FIG. A2. Angle of attack $\alpha$ of an airfoil (based on Brandt et al. 2004, their Fig. 3.13).

\section{REFERENCES}

Amante, C., and B. W. Eakins, 2009: ETOPO1 1 Arc-Minute Global Relief Model: Procedures, data sources and analysis. NOAA National Geophysical Data Center, 19 pp.

Bacmeister, J. T., M. R. Schoeberl, L. R. Lait, P. A. Newman, and B. Gary, 1990: ER-2 mountain wave encounter over Antarctica: Evidence for blocking. Geophys. Res. Lett., 17, 81-84, https:// doi.org/10.1029/GL017i001p00081.

Bauer, P., A. Thorpe, and G. Brunet, 2015: The quiet revolution of numerical weather prediction. Nature, 525, 47-55, https:// doi.org/10.1038/nature14956.

Bougeault, P., and Coauthors, 1993: The Atmospheric Momentum Budget over a major mountain range: First results of the PYREX field program. Ann. Geophys., 11, 395-418.

— , and Coauthors, 2001: The MAP Special Observing Period. Bull. Amer. Meteor. Soc., 82, 433-462, https://doi.org/10.1175/ 1520-0477(2001)082<0433:TMSOP >2.3.CO;2.

— A. J. Clar, B. Benech, B. Carissimo, J. Pelon, and E. Richard, 1990: Momentum budget over the Pyrénées: The PYREX experiment. Bull. Amer. Meteor. Soc., 71, 806-818, https:// doi.org/10.1175/1520-0477(1990)071<0806:MBOTPT>2.0.CO;2.

Bramberger, M., and Coauthors, 2017: Does strong tropospheric forcing cause large-amplitude mesospheric gravity waves? A DEEPWAVE case study. J. Geophys. Res. Atmos., 122, 11422-11 443, https://doi.org/10.1002/2017JD027371.

Brandt, S., R. J. Stiles, J. J. Bertin, and R. Whitford, 2004: Introduction to Aeronautics: A Design Perspective. AIAA Education Series, American Institute of Aeronautics and Astronautics, 508 pp.

Champagne, F. H., 1978: The fine-scale structure of the turbulent velocity field. J. Fluid Mech., 86, 67-108, https://doi.org/ 10.1017/S0022112078001019.

Chan, K. R., and Coauthors, 1993: A case study of the mountain lee wave event of January 6, 1992. Geophys. Res. Lett., 20, 25512554, https://doi.org/10.1029/93GL01964.

Coffel, E., and R. Horton, 2015: Climate change and the impact of extreme temperatures on aviation. Wea. Climate Soc., 7, 94-102, https://doi.org/10.1175/WCAS-D-14-00026.1.

Corda, S., 2017: Introduction to Aerospace Engineering with a Flight Test Perspective. Aerospace Series, John Wiley and Sons, 928 pp.

Cornman, L. B., 2016: Airborne in situ measurements of turbulence. Aviation Turbulence, R. Sharman and T. Lane, Eds., Springer, 97-102, https://doi.org/10.1007/978-3-319-23630-8_5.

_ C. S. Morse, and G. Cunning, 1995: Real-time estimation of atmospheric turbulence severity from in-situ aircraft measurements. J. Aircr., 32, 171-177, https://doi.org/10.2514/3.46697.

Delay, R. D., and J. A. Dutton, 1971: An analysis of conditions associated with an occurrence of stratospheric CAT. J. Atmos. Sci., 28, 1272-1279, https://doi.org/10.1175/1520-0469(1971) $028<1272$ :AAOCAW $>2.0$.CO;2.

Dörnbrack, A., S. Gisinger, M. C. Pitts, L. R. Poole, and M. Maturilli, 2017: Multilevel cloud structures over Svalbard. Mon. Wea. Rev., 145, 1149-1159, https://doi.org/10.1175/MWR-D-16-0214.1.
Doyle, J. D., M. A. Shapiro, Q. Jiang, and D. L. Bartels, 2005: Large-amplitude mountain wave breaking over Greenland. J. Atmos. Sci., 62, 3106-3126, https://doi.org/10.1175/JAS3528.1.

Dutton, J. A., 1969: An energy budget for a layer of stratospheric CAT. Radio Sci., 4, 1137-1142, https://doi.org/10.1029/ RS004i012p01137.

Eckermann, S. D., A. Dörnbrack, H. Flentje, S. B. Vosper, M. J. Mahoney, T. P. Bui, and K. S. Carslaw, 2006: Mountain waveinduced polar stratospheric cloud forecasts for aircraft science flights during SOLVE/THESEO 2000. Wea. Forecasting, 21, 42-68, https://doi.org/10.1175/WAF901.1.

Eliassen, A., and E. Palm, 1961: On the transfer of energy in stationary mountain waves. Geofys. Publ., 22, 1-23.

Fritts, D. C., and M. J. Alexander, 2003: Gravity wave dynamics and effects in the middle atmosphere. Rev. Geophys., 41, 1003, https://doi.org/10.1029/2001RG000106.

_ , and Coauthors, 2016: The Deep Propagating Gravity Wave Experiment (DEEPWAVE): An airborne and ground-based exploration of gravity wave propagation and effects from their sources throughout the lower and middle atmosphere. Bull. Amer. Meteor. Soc., 97, 425-453, https://doi.org/10.1175/BAMS-D-14-00269.1.

Giez, A., C. Mallaun, M. Zöger, A. Dörnbrack, and U. Schumann, 2016: Comparison of static pressure from aircraft trailing cone measurements and numerical weather prediction analysis. AIAA Atmospheric Flight Mechanics Conf., Washington, DC, AIAA, https://doi.org/10.2514/6.2016-3707.

Grubišić et al., 2008Grubišić, V., and Coauthors, 2008: The TerrainInduced Rotor Experiment: A field campaign overview including observational highlights. Bull. Amer. Meteor. Soc., 89, 1513-1533, https://doi.org/10.1175/2008BAMS2487.1.

Hoblit, F. M., 1988: Gust Loads on Aircraft: Concepts and Applications. AIAA Education Series, Institute of Aeronautics and Astronautics, $306 \mathrm{pp}$.

Hólm, E., R. Forbes, S. Lang, L. Magnusson, and S. Malardel, 2016: New model cycle brings higher resolution. ECMWF Newsletter, No. 147, ECMWF, Reading, United Kingdom, 14-19, http://www.ecmwf.int/sites/default/files/elibrary/2016/16299newsletter-no147-spring-2016.pdf.

IATA, 2017: IATA forecasts passenger demand to double over 20 years. Press release No. 59, accessed 28 November 2017 , http://www.iata.org/pressroom/pr/Pages/2016-10-18-02.aspx.

ICAO, 2001: Meteorological service for international air navigation. Annex 3 to the Convention on International Civil Aviation, 14th ed. International Civil Aviation Organization Doc., 128 pp.

Irvine, E. A., K. P. Shine, and M. A. Stringer, 2016: What are the implications of climate change for trans-Atlantic aircraft routing and flight time? Transp. Res., 47D, 44-53, https:// doi.org/10.1016/j.trd.2016.04.014.

Jiang, Q., and J. D. Doyle, 2004: Gravity wave breaking over the central Alps: Role of complex terrain. J. Atmos. Sci., 61 , 2249-2266, https://doi.org/10.1175/1520-0469(2004)061<2249: GWBOTC $>2.0 . \mathrm{CO} ; 2$.

Karnauskas, K. B., J. P. Donnelly, H. C. Barkley, and J. E. Martin, 2015: Coupling between air travel and climate. Nat. Climate Change, 5, 1068-1073, https://doi.org/10.1038/nclimate2715.

Kennedy, P. J., and M. A. Shapiro, 1975: The energy budget in a clear air turbulence zone as observed by aircraft. Mon. Wea. Rev., 103, 650-654, https://doi.org/10.1175/1520-0493(1975) $103<0650$ :TEBIAC $>2.0$. CO; 2 .

Kim, J.-H., W. N. Chan, B. Sridhar, R. D. Sharman, P. D. Williams, and M. Strahan, 2016: Impact of the North Atlantic Oscillation on transatlantic flight routes and clear-air turbulence. 
J. Appl. Meteor. Climatol., 55, 763-771, https://doi.org/ 10.1175/JAMC-D-15-0261.1.

Lane, T. P., J. D. Doyle, R. D. Sharman, M. A. Shapiro, and C. D. Watson, 2009: Statistics and dynamics of aircraft encounters of turbulence over Greenland. Mon. Wea. Rev., 137, 2687-2702, https://doi.org/10.1175/2009MWR2878.1.

—, R. D. Sharman, S. B. Trier, R. G. Fovell, and J. K. Williams, 2012: Recent advances in the understanding of near-cloud turbulence. Bull. Amer. Meteor. Soc., 93, 499-515, https:// doi.org/10.1175/BAMS-D-11-00062.1.

Lester, P., 1993: Turbulence: A New Perspective for Pilots. Jeppesen Sanderson, $212 \mathrm{pp}$.

Leutbecher, M., and H. Volkert, 2000: The propagation of mountain waves into the stratosphere: Quantitative evaluation of threedimensional simulations. J. Atmos. Sci., 57, 3090-3108, https:// doi.org/10.1175/1520-0469(2000)057<3090:TPOMWI>2.0.CO;2.

MacCready, P. B., 1964: Standardization of gustiness values from aircraft. J. Appl. Meteor., 3, 439-449, https://doi.org/10.1175/ 1520-0450(1964)003<0439:SOGVFA > 2.0.CO;2.

Malardel, S., and N. P. Wedi, 2016: How does subgrid-scale parametrization influence nonlinear spectral energy fluxes in global NWP models? J. Geophys. Res. Atmos., 121, 5395-5410, https://doi.org/10.1002/2015JD023970.

Mallaun, C., A. Giez, and R. Baumann, 2015: Calibration of 3-D wind measurements on a single-engine research aircraft. Atmos. Meas. Tech., 8, 3177-3196, https://doi.org/10.5194/amt-8-3177-2015.

Ólafsson, H., and H. Ágústsson, 2009: Gravity wave breaking in easterly flow over Greenland and associated low level barrierand reverse tip-jets. Meteor. Atmos. Phys., 104, 191-197, https://doi.org/10.1007/s00703-009-0024-9.

Oncley, S. P., C. A. Friehe, J. C. Larue, J. A. Businger, E. C. Itsweire, and S. S. Chang, 1996: Surface-layer fluxes, profiles, and turbulence measurements over uniform terrain under nearneutral conditions. J. Atmos. Sci., 53, 1029-1044, https://doi.org/ 10.1175/1520-0469(1996)053<1029:SLFPAT $>2.0 . C O ; 2$.

Piper, M., and J. K. Lundquist, 2004: Surface layer turbulence measurements during a frontal passage. J. Atmos. Sci., 61 , 1768-1780, https://doi.org/10.1175/1520-0469(2004)061<1768: SLTMDA $>2.0 . C O ; 2$.

Prusa, J. M., P. K. Smolarkiewicz, and A. A. Wyszogrodzki, 2008: EULAG, a computational model for multiscale flows. Comput. Fluids, 37, 1193-1207, https://doi.org/10.1016/ j.compfluid.2007.12.001.

Romps, D. M., J. T. Seeley, D. Vollaro, and J. Molinari, 2014: Projected increase in lightning strikes in the United States due to global warming. Science, 346, 851-854, https://doi.org/ 10.1126/science. 1259100 .

Schmid, H., and A. Dörnbrack, 1999: Simulation of breaking gravity waves during the south foehn of January 7-13, 1996. Contrib. Atmos. Phys., 72, 287-301.

Shapiro, M. A., 1976: The role of turbulent heat flux in the generation of potential vorticity in the vicinity of upper-level jet stream systems. Mon. Wea. Rev., 104, 892-906, https://doi.org/10.1175/ 1520-0493(1976)104<0892:TROTHF>2.0.CO;2.

Sharman, R. D., and J. M. Pearson, 2017: Prediction of energy dissipation rates for aviation turbulence. Part I: Forecasting nonconvective turbulence. J. Climate Appl. Meteor., 56, 317-337, https://doi.org/10.1175/JAMC-D-16-0205.1.

— C. Tebaldi, G. Wiener, and J. Wolff, 2006: An integrated approach to mid- and upper-level turbulence forecasting. Wea. Forecasting, 21, 268-287, https://doi.org/10.1175/WAF924.1.

_ J. D. Doyle, and M. A. Shapiro, 2012a: An investigation of a commercial aircraft encounter with severe clear-air turbulence over western Greenland. J. Appl. Meteor. Climatol., 51, 42-53, https://doi.org/10.1175/JAMC-D-11-044.1.

— S. B. Trier, T. P. Lane, and J. D. Doyle, 2012b: Sources and dynamics of turbulence in the upper troposphere and lower stratosphere: A review. Geophys. Res. Lett., 39, L12803, https:// doi.org/10.1029/2012GL051996.

——, L. B. Cornman, G. Meymaris, J. Pearson, and T. Farrar, 2014: Description and derived climatologies of automated in situ eddy-dissipation-rate reports of atmospheric turbulence. J. Climate Appl. Meteor., 53, 1416-1432, https:// doi.org/10.1175/JAMC-D-13-0329.1.

Smith, R. B., B. K. Woods, J. Jensen, W. A. Cooper, J. D. Doyle, Q. Jiang, and V. Grubišić, 2008: Mountain waves entering the stratosphere. J. Atmos. Sci., 65, 2543-2562, https://doi.org/ 10.1175/2007JAS2598.1.

- , and Coauthors, 2016: Stratospheric gravity wave fluxes and scales during DEEPWAVE. J. Atmos. Sci., 73, 2851-2869, https://doi.org/10.1175/JAS-D-15-0324.1.

Sorbjan, Z., 1996: Numerical study of penetrative and "solid lid" nonpenetrative convective boundary layers. J. Atmos. Sci., 53, 101-112, https://doi.org/10.1175/1520-0469(1996)053<0101: NSOPAL $>2.0 . \mathrm{CO} ; 2$.

Strauss, L., S. Serafin, S. Haimov, and V. Grubii, 2015: Turbulence in breaking mountain waves and atmospheric rotors estimated from airborne in situ and Doppler radar measurements. Quart. J. Roy. Meteor. Soc., 141, 3207-3225, https://doi.org/10.1002/qj.2604.

Torrence, C., and G. P. Compo, 1998: A practical guide to wavelet analysis. Bull. Amer. Meteor. Soc., 79, 61-78, https://doi.org/ 10.1175/1520-0477(1998)079<0061:APGTWA > 2.0.CO;2.

Tvaryanas, A. P., 2003: Epidemiology of turbulence-related injuries in airline cabin crew, 1992-2001. Aviat. Space Environ. Med., 74, 970-976.

Večenaj, Ž., D. Belušić, V. Grubišić, and B. Grisogono, 2012: Alongcoast features of Bora-related turbulence. Bound.-Layer Meteor., 143, 527-545, https://doi.org/10.1007/s10546-012-9697-6.

Vinnichenko, N. K., N. Z. Pinus, S. M. Shmeter, and G. N. Shur, 1980: Turbulence in the Free Atmosphere. Plenum, 310 pp.

Wagner, J., and Coauthors, 2017: Observed versus simulated mountain waves over Scandinavia-Improvement of vertical winds, energy and momentum fluxes by enhanced model resolution? Atmos. Chem. Phys., 17, 4031-4052, https://doi.org/ 10.5194/acp-17-4031-2017.

Wedi, N. P., 2014: Increasing horizontal resolution in numerical weather prediction and climate simulations: Illusion or panacea? Philos. Trans. Roy. Soc., A372, 20130289, https://doi.org/ 10.1098/rsta.2013.0289.

Welch, P. D., 1967: The use of fast Fourier transform for the estimation of power spectra: A method based on time averaging over short, modified periodograms. IEEE Trans. Audio Electroacoust., 15, 70-73, https://doi.org/10.1109/TAU.1967.1161901.

Williams, P. D., 2016: Transatlantic flight times and climate change. Environ. Res. Lett., 11, 024008, https://doi.org/10.1088/17489326/11/2/024008.

2017: Increased light, moderate, and severe clear-air turbulence in response to climate change. Adv. Atmos. Sci., 34, 576586, https://doi.org/10.1007/s00376-017-6268-2.

Wolff, J. K., and R. D. Sharman, 2008: Climatology of upper-level turbulence over the contiguous United States. J. Climate Appl. Meteor., 47, 2198-2214, https://doi.org/10.1175/2008JAMC1799.1.

Woods, B. K., and R. B. Smith, 2010: Energy flux and wavelet diagnostics of secondary mountain waves. J. Atmos. Sci., 67, 3721-3738, https://doi.org/10.1175/2009JAS3285.1. 